\title{
SEleCtion INTO AND ACROSS CREDIT CONTRACTS: THEORY AND FIELD RESEARCH
}

\author{
by
}

Christian Ahlin and Robert Townsend

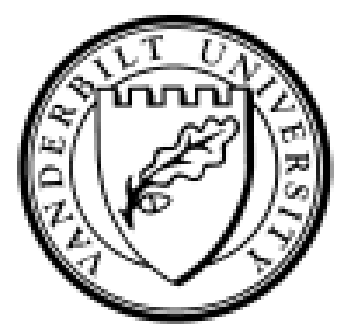

Working Paper No. 03-W23

October 2003

\section{DEPARTMENT OF ECONOMICS \\ VANDERBILT UNIVERSITY \\ NASHVILLE, TN 37235}

www.vanderbilt.edu/econ 


\title{
Selection into and across Credit Contracts: Theory and Field Research
}

\author{
Christian Ahlin and Robert Townsend*
}

October 2003

\begin{abstract}
Various theories make predictions about the relative advantages of individual loans versus joint liability loans. If we imagine that lenders facing moral hazard make relative performance comparisons in determining stringency in repayment, then individual loans should vary positively with covariance of output across funded projects. Relatively new work also highlights inequality and heterogeneity in preferences, establishing that wealth of the agents relative to the bank, and wealth dispersion among potential joint liability partners, are important factors determining the likelihood of the joint liability regime. An alternative imperfect information model also addresses the question of which agents will accept a group contract and borrow and which will pursue outside options. We attempt to test these various models using relatively rich data gathered in field research in Thailand, measuring not only the presence of joint liability versus individual loans, but also measuring various of the key variables suggested by these theories. As predicted by one of the theories, the prevalence of joint liability contracts relative to individual contracts exhibits a U-shaped relationship with the wealth of the borrowing pair and increases with the wealth dispersion. (We control for wealth that can be used as collateral.) Contrary to one theory, we find no evidence joint liability borrowing becomes less likely as covariance of output increases. We do find, consistent with our modified version of the model with adverse selection, that higher correlation makes joint liability borrowing more likely relative to all outside options. We also find direct evidence consistent with adverse selection in the credit market, in that the likelihood of joint-liability borrowing increases the lower is the probability of project success. We are able to distinguish this result from an alternative moral hazard explanation. Strikingly, most of the results disappear if we do not condition the sample according to the dictates of the models.
\end{abstract}

*We thank Eric Bond, William Collins, Bernard Salanie, and seminar participants at Chicago, Vanderbilt, Stanford Institute for Theoretical Economics, and Yale for helpful comments. Financial support from the National Institute of Health and the National Science Foundation (including its Graduate Research Fellowship Program) is gratefully acknowledged. All errors are ours. 


\section{Introduction}

The literature on micro credit as a major tool against world poverty is polarized over the debate of the virtues of individual versus group, joint liability lending. For the most part, only one contract per lender is observed, e.g., group lending under the Grameen Bank in Bangladesh and individual loans under BRI in Indonesia. It is thus difficult to make progress in the debate. We do not see what would happen if the alternative contract were available, not to mention all the difficulties inherent in cross country comparisons. Here we take advantage of the menu of contracts offered by a dominant rural lender in a single country and some unusual data gathered in field research to make some headway on the issue. Potential borrowers from the $\mathrm{BAAC}^{1}$ in Thailand decide whether to borrow at all, and if so, whether to borrow as individuals or under joint liability. That is, potential borrowers select into and across loan contracts. There is in fact much variation in these choices in the data. We thus use the data to test various well-known models from the contract theory, mechanism design literature.

One interpretation of group loans is as a way for the lender to encourage trade, or contracting, between the borrowers. Group loans are accompanied by required group meetings and explicit group-related contingencies. They are also formed mostly autonomously by group members themselves. This kind of lending arrangement would seem to facilitate (or indeed encourage) contracting among the borrowers. The advantage of such interaction would be enhanced ability to monitor and enforce intra-group agreements on actions and transfers (i.e. risk sharing). The downside of such interaction is the ability to collude against the lender, coordinating in the choice of low mutual effort or reallocating internal resources (e.g., tunneling). Under individual loans, without collusion, the lender can gage if one borrower has been diligent by looking to see if other individual borrowers are doing well. Under this interpretation of group and individual loans, it is not obvious the kind of loan for which moral hazard considerations argue.

Indeed theories of individual vs. group loans often do not make unequivocal predictions. It has been shown, for example by Hölmstrom and Milgrom (1990) (hereafter HM), that a principal, or lender, faced with the problem of inducing effort from agents, or borrowers, when effort is imperfectly observed can use correlation between the random component of borrowers' returns to mitigate this imperfect information. The higher this technological correlation, the more effectively is the information problem dealt with in such a relative performance regime, and the risk cost of high-powered incentives decreases. This type of result relies on the borrowers acting non-cooperatively. If they instead act cooperatively and are assumed able to honor side-contracts to ensure risk and enforce actions, a relative performance regime can be manipulated to lead to adverse results. The lender's hands are thus tied. However, the ability of the borrowers to coordinate and share risk among themselves lowers risk costs and raises total surplus, all else equal. The closer to zero is the correlation between the borrowers' returns, the greater the scope for internal risk sharing. As intuition suggests and Hölmstrom and Milgrom show formally, it would be Pareto optimal for the borrowers to be acting non-cooperatively if technological correlation is high enough, and cooperatively if it is low enough. In principle, this is a testable implication.

\footnotetext{
${ }^{1} \mathrm{BAAC}$ is short for the Bank for Agriculture and Agricultural Cooperatives.
} 
Prescott and Townsend (1999) (hereafter PT) address similar questions but focus instead on wealth levels of borrowers relative to the lender and wealth dispersion across borrowers. They offer an extended version of the above-mentioned unobserved effort model, generalized in several directions, but without closed form solutions available. In simulations, they find that for asymmetric enough Pareto weights on the two borrowers, interpretable as high wealth dispersion, the cooperative regime dominates. When the weights are more similar, the noncooperative regime dominates. Apparently the cooperative regime is better at extracting effort from the low-weight borrower. Further, the cooperative regime dominates for high enough or low enough reservation payoff of the lender, interpretable as the inverse of the borrowers' wealth, while an intermediate value makes the non-cooperative regime optimal. Again, both these predictions are in principle testable.

Another interpretation, perhaps more common, of a joint liability, group loan is that an individual borrower promises to repay a lender if able but a second, co-signer of that same loan promises to repay if the first borrower is unable. Group loans are a version of this in which each member of the group is borrowing and jointly liable for the loans of the others. In contrast, under individual liability, the borrower enters into a contract with the lender, potentially offering collateral, and no third parties are directly involved.

Under this interpretation, joint liability loans in conjunction with good local information on risk types are also thought to help overcome a different problem, adverse selection. Some borrowers are inherently more risky than others. In a setting of limited, individual liability and lender ignorance of risk-type, risky borrowers are in effect subsidized by safe ones. In some instances this cuts out socially productive loans to safe borrowers. ${ }^{2}$ Joint liability, through homogeneous matching among risk types, can reduce the subsidy from safe to risky borrowers and thus mitigate (though not necessarily eliminate) the adverse selection problem, drawing back into the market relatively safe borrowers. Fundamental to this argument, of course, is the existence of an adverse selection problem in the credit market, which some argue is negligible in practice due to banks' ability to collect information and their offering of other incentives. ${ }^{3}$

Ghatak (1999) addresses these questions using a model that is our focus here. We modify this model to introduce correlation in borrower returns and find that borrowers with higher correlation of returns will self-select into group contracts (a testable proposition). They do this because correlation raises their payoff of borrowing by lowering the chances of facing liability for their partner's loan. Ghatak's model also exhibits the well-known prediction that in the context of limited liability, the relatively risky agents are the ones who opt to borrow. Ausubel (1999) tests this proposition with data from credit card companies: those willing to select into higher interest rates are more likely to default. A parallel insurance literature also tests whether households paying for more complete coverage are more likely to experience the adverse, insured event. (See the literature review in Chiappori and Salonie (2000)). Here we take advantage of measurements of risk type of those who also choose not to borrow and offer a direct test of this prediction of the adverse selection model.

We attempt to test these predictions from the various models about which kinds of agents will borrow, and under which kinds of contracts, using relatively rich data gathered

\footnotetext{
${ }^{2}$ This kind of adverse selection dates back at least to Stiglitz and Weiss (1981).

${ }^{3}$ See Robinson (2001) for example.
} 
in field research in Thailand. We link the non-cooperative regime in the theory (of HM and PT) with individual loans in the data, and the cooperative regime in the theory with joint liability, group loans in the data. The link is imperfect, but this kind of contract variation is a plausible means the lender can use to encourage or discourage side-contracting and cooperation. When testing Ghatak, individual loans are linked with an outside option in the theory, and of course group loans are those where there is joint liability. ${ }^{4}$ We also have measures for wealth, wealth dispersion, technological correlation, and the risk of the borrowers, as well as numerous controls.

Our association of the loan types in the theory with analogs in actual practice deserves some elaboration. The Bank for Agriculture and Agricultural Cooperatives (BAAC) is the primary institutional lender in rural Thailand: for example $64 \%$ of the institutional loans in our sample are from the BAAC. The BAAC does offer both individual loans and joint liability loans. Policy dictates that to receive the latter, one must form or join an official BAAC-registered borrowing group and enter into a joint liability agreement. A box denoting that the group is the collateral is checked off on the loan form, and sometimes a particular member in the group is named as a cosigner. In contrast, individual loans must be guaranteed by some form of collateral, usually land. However, the BAAC does not readily foreclose on either kind of loan, i.e. does not always go after the co-signer or confiscate individual collateral, respectively. This supports the HM and PT interpretation of loan repayments as output-contingent and the Ghatak assumption that no payment is demanded from a borrower whose project fails. Rather, it has in place a risk-contingency system, as documented in Townsend and Yaron (2001), for example. Farmers experiencing force majeur events report their difficulties to the local branch and a credit officer visits the village (the farmer and neighboring households) to verify the adverse event. To an approximation then, information on output, or at least ability to pay, is observable by the lender. The loan can be rescheduled, and in some instances interest and even part of principal forgiven, as if an insurance indemnity had kicked in. Thus group, and to a significant degree individual, credit contracts are state contingent loan repayment agreements. ${ }^{5}$ More generally the BAAC is well positioned to make relative performance comparisons in deciding what to do about repayment problems.

The BAAC is not the only lender. In our data we have a complete enumeration of loans outstanding or repaid in the last twelve months, and for each loan the household respondent is asked what if any collateral was used (land title, cosigner, other). Among these are loans from village funds, money lenders, commercial banks, and the informal sector. We also test the models on a larger sample of individual and co-signed loans from institutional lenders other than the BAAC.

To test the implications of the relative performance vs. joint-liability literature, we restrict the sample to those who have had a loan outstanding in the last twelve months from

\footnotetext{
${ }^{4}$ Ghatak shows group loans dominate individual loans for those without collateral, sometimes in a Pareto sense and always in terms of total surplus. Thus theory suggests individual loans in the data must be collateralized.

${ }^{5}$ Under the framework of HM and PT individual loans are fully state contingent (subject to moral hazard) while under our interpretation of the Ghatak framework, individual loans are fully backed by physical collateral and are not state contingent. The truth is probably between the two extremes. We carry out robustness checks when we test the models.
} 
the BAAC, or another lender, and throw out of the sample those who did not borrow at all. Likewise, to test the adverse selection models of the literature, we focus on the decision whether to borrow under joint liability or any alternative (not borrow at all or borrow under individual liability). ${ }^{6}$

As predicted by Prescott and Townsend, the prevalence of joint liability contracts relative to individual contracts exhibits a U-shaped relationship with the wealth of the borrowing pair and increases with the wealth dispersion. The latter result is especially robust. The results surface only when we limit the sample to households with either a group or an individual loan, but not both. This is what theory would suggest, since it compares the two types of contracts against each other. The results do not appear to be due to a conventional collateral effect (in which higher wealth enables households to borrow without cosignors); we separate out and control for the subset of wealth that is most commonly used as collateral.

Contrary to the Hölmstrom and Milgrom theory, we find no evidence joint liability borrowing becomes less likely as covariance of output increases. This is true when restricting the sample only to those with group or individual loans. When we use the full sample, however, as the Ghatak model would dictate, we find some evidence for the opposite. That is, we find that higher correlation makes joint liability borrowing more likely relative to all outside options, just as our modified version of Ghatak's model suggests.

Finally, we find direct evidence consistent with the prediction of adverse selection in the credit market, in that the likelihood of joint-liability borrowing increases the lower is the probability of project success. This result only appears when the full sample is used. Thus the more risky households are borrowing. There is as already noted a related theory-based empirical literature testing for imperfect information in insurance contract, but as Chiappori, Jullien, Salanie and Salanie (2002) emphasize it is difficult to infer if accident probabilities increase for those purchasing more complete coverage because of adverse selection (ex ante selection) or moral hazard (ex post shirking). Here we further restrict our sample to those who have borrowed in the last year but are not currently doing so, and find that the adverse selection remains a force in the data.

Strikingly, as alluded to above, most of these results confirming the models predictions disappear if we do not condition the sample according to the dictates of the models.

\section{Theories and Implications}

\subsection{Moral Hazard and Technological Correlation}

We focus initially on selection across contracts, given that borrowing is taking place. Correlation of output across agents is related by Holmström and Milgrom (1990), HM, in the context of unobserved actions, to the optimality of an individualistic, relative performance regime vis a vis a cooperative regime. They find that there exists a cutoff technological correlation coefficient, call it $\bar{\rho}$. For $\rho<\bar{\rho}$, the optimal contract employs a cooperative or group regime; for $\rho>\bar{\rho}$, the optimal contract employs a relative performance regime. Thus, one should expect to see more of the group regime among agents whose output is less correlated.

\footnotetext{
${ }^{6}$ The results are robust to the inclusion of those borrowing as individuals with those borrowing under joint liability and to their exclusion.
} 
Assume there are two agents, or borrowers, indexed by $i$. Each produces output $q_{i}$ as a function of his effort $e_{i}$ and some random shock $\varepsilon_{i}$. Output $q_{i}$ could be made to vary with loan size also, but the latter is regarded as fixed and dropped from the notation. Output is then additive in effort and the shock:

$$
q_{i}=e_{i}+\varepsilon_{i}, \quad i=1,2 .
$$

The epsilons are distributed joint-normally with means zero and variance-covariance matrix $\Sigma$, where

$$
\boldsymbol{\Sigma} \equiv\left[\begin{array}{cc}
\sigma_{1}^{2} & \sigma_{12} \\
\sigma_{12} & \sigma_{2}^{2}
\end{array}\right]
$$

The point is that a higher effort $e_{i}$ makes higher output $q_{i}$ more likely, but there is noise and the returns may be correlated. Note also that the projects may differ in risk $\sigma_{i}^{2}$. Let $\boldsymbol{q}$ and $\boldsymbol{e}$ be the vectors $\left[\begin{array}{ll}q_{1} & q_{2}\end{array}\right]^{T}$ and $\left[e_{1} e_{2}\right]^{T}$, respectively. ${ }^{7}$ Since only the $q_{i}^{\prime} s$ are publicly observed, borrower payoffs must be in terms of them. Attention is restricted to contracts giving agent $i$ consumption $c_{i}$ as a linear function of output:

$$
c_{i}\left(\boldsymbol{q} ; \kappa_{i 0}, \boldsymbol{\kappa}_{i}\right)=\kappa_{i 0}+\boldsymbol{\kappa}_{i}^{T} \boldsymbol{q}, i=1,2,
$$

where $\boldsymbol{\kappa}_{i}=\left[\begin{array}{ll}\kappa_{i 1} & \kappa_{i 2}\end{array}\right]^{T}$. Further let $\boldsymbol{\kappa} \equiv\left\{\kappa_{i j}\right\}$, for $i=1,2$ and $j=0,1,2 ; \boldsymbol{\kappa}$ is just the collection of all the compensation parameters. Agents maximize expected utility, where utility of consumption is of exponential functional form with coefficient of absolute risk aversion $r_{i}$, and $C_{i}(\cdot)$ gives the disutility of effort (strictly convex):

$$
U_{i}\left(c_{i}, e_{i}\right)=-e^{-r_{i} c_{i}-C_{i}\left(e_{i}\right)} .
$$

This gives rise to the well-known certainty equivalence utility function

$$
C E_{i}(\boldsymbol{e} ; \boldsymbol{\kappa})=\kappa_{i 0}+\boldsymbol{\kappa}_{i}^{T} \boldsymbol{e}-C_{i}\left(e_{i}\right)-(1 / 2) r_{i} \boldsymbol{\kappa}_{i}^{T} \boldsymbol{\Sigma} \boldsymbol{\kappa}_{i}
$$

for agent $i$, where $\boldsymbol{\kappa}_{i}^{T} \boldsymbol{\Sigma} \boldsymbol{\kappa}_{i}=\kappa_{i 1}^{2} \sigma_{1}^{2}+\kappa_{i 2}^{2} \sigma_{2}^{2}+2 \kappa_{i 1} \kappa_{i 2} \sigma_{12}$. Note that diversity in cost of effort and risk aversion is allowed. The lender is risk neutral and thus has certainty equivalence utility of

$$
C E_{p}(\boldsymbol{e} ; \boldsymbol{\kappa})=\left(\mathbf{1}-\boldsymbol{\kappa}_{1}-\boldsymbol{\kappa}_{2}\right)^{T} \boldsymbol{e}-\kappa_{10}-\kappa_{20} .
$$

Suppose the lender can deal with each borrower individually. Then the lender sets both contracts to maximize his payoff subject to agents' participation constraints and incentive compatibility constraints. In general, the individual participation constraints might matter, but since the model exhibits transferable utility, the lender's problem is essentially equivalent to maximizing total surplus (the sum of all payoffs) subject to the incentive compatibility constraints. ${ }^{8}$ Thus, the optimal contract chooses $\boldsymbol{\kappa}$ to maximize

$$
e_{1}+e_{2}-C_{1}\left(e_{1}\right)-C_{2}\left(e_{2}\right)-1 / 2 r_{1} \boldsymbol{\kappa}_{1}^{T} \boldsymbol{\Sigma} \boldsymbol{\kappa}_{1}-1 / 2 r_{2} \boldsymbol{\kappa}_{2}^{T} \boldsymbol{\Sigma} \boldsymbol{\kappa}_{2}
$$

subject to the first-order conditions for effort: $C_{i}^{\prime}\left(e_{i}\right)=\kappa_{i i}, i=1,2$.

\footnotetext{
${ }^{7}$ That is, $\boldsymbol{q}$ is a column vector and $\boldsymbol{q}^{T}$ a row vector; similarly for $\boldsymbol{e}$ and other vectors defined below.

${ }^{8}$ To see this, first note that a contract maximizing total surplus subject to incentive constraints, TSC, gives the same surplus as that as that of a contract maximizing total surplus subject to incentive constraints and agents' utility equalling their reservation level, TSCP. This is true because any contract can be transformed into one in which agents' participation constraints bind, without affecting incentive constraints or total surplus, through lump-sum utility transfers between lender and borrowers using the intercept terms $\kappa_{10}$ and
} 
Total surplus is expected output less costs of effort and risk costs. The optimal solution satisfies

$$
\kappa_{i i}=\frac{1}{1+r_{i} \sigma_{i}^{2}\left(1-\rho^{2}\right) C_{i}^{\prime \prime}}, \kappa_{i j}=-\kappa_{i i} \sigma_{12} / \sigma_{j}^{2} ; \quad i=1,2, j=1,2, j \neq i
$$

where $\rho \equiv \sigma_{12} / \sigma_{1} \sigma_{2}$ is the correlation coefficient. Note that the direct, own-production term $\kappa_{i i}$ decreases in $\sigma_{i}^{2}$ and $r_{i}$ and the cross term $\kappa_{i j}$ varies inversely with the technological correlation $\sigma_{12}$ and (in absolute value) with the risk of the other borrower $\sigma_{j}^{2}$. The total risk cost under this optimal contract can be calculated to be:

$$
\left(1-\rho^{2}\right) \frac{r_{1} \kappa_{11}^{2} \sigma_{1}^{2}+r_{2} \kappa_{22}^{2} \sigma_{2}^{2}}{2} .
$$

If $\rho=1$ then relative performance evaluation works perfectly well, all deviations in effort being perfectly detectable and the lender offering full insurance. The risk sharing occurs because the correlation between shocks mitigates the principal's lack of information about the agents' efforts.

The preceding analysis has assumed that borrowers could not observe each other's actions or contract with each other in any way. Next, the case is considered where the two borrowers can cooperate, as is presumably easier within a joint liability group. In particular, they can commit to transfers with each other conditional on actions and outcomes. ${ }^{9}$ This allows them to mutually reinsure each other and to coordinate to an agreed upon set of actions. The contracts they can write will be of the form

$$
\tau(\boldsymbol{e}, \boldsymbol{x})=\boldsymbol{\gamma}^{T} \boldsymbol{x}+t\left(e_{1}, e_{2}\right)
$$

where $\tau(\boldsymbol{e}, \boldsymbol{x})$ gives the net transfer from agent 1 to agent 2 as a result of actions $\boldsymbol{e}$ and output realizations $\boldsymbol{x}$. The function $t(\cdot)$ allows the pair to enforce any set of actions as a Nash equilibrium. ${ }^{10}$ The mutual insurance agreements, for which coefficient $\gamma$ denotes the vector $\left[\begin{array}{ll}\gamma_{1} & \gamma_{2}\end{array}\right]^{T}$, are restricted to be linear in output, as above.

HM assume the pair will choose $t(\cdot)$ and $\gamma$ to reach a Pareto optimal set of actions and transfers. Again, given transferable utility (which can be done within the group using $t(\cdot)$, for example), this implies the pair will maximize joint surplus. Given the external borrowing contract with its incentives $\boldsymbol{\kappa}$, the two borrowers thus choose $(\boldsymbol{e}, \boldsymbol{\gamma})$ to maximize

$$
\left(\boldsymbol{\kappa}_{1}+\boldsymbol{\kappa}_{2}\right)^{T} \boldsymbol{e}-C_{1}\left(e_{1}\right)-C_{2}\left(e_{2}\right)-1 / 2 r_{1}\left(\boldsymbol{\kappa}_{1}-\boldsymbol{\gamma}\right)^{T} \boldsymbol{\Sigma}\left(\boldsymbol{\kappa}_{1}-\boldsymbol{\gamma}\right)-1 / 2 r_{2}\left(\boldsymbol{\kappa}_{2}+\boldsymbol{\gamma}\right)^{T} \boldsymbol{\Sigma}\left(\boldsymbol{\kappa}_{2}+\boldsymbol{\gamma}\right)
$$

$\kappa_{20}$. Further, note that an optimal contract for the lender, OC, must give at least the same total surplus as TSCP. If it produced a lower surplus, i.e. sum of payoffs, the lender would be worse off under OC, since the borrowers can be no worse off than they are under TSCP (under which they receive their reservation utility level). But then OC would not be optimal, since TSCP gives a higher lender payoff and satisfies the same constraints. Of course, OC cannot give a greater total surplus than TSCP, since TSCP maximizes total surplus subject to the same constraints. Thus OC gives the same total surplus as TSCP, which gives the same total surplus as TSC. That is, any optimal contract maximizes total surplus.

${ }^{9}$ Interestingly, HM show that as long as the pair can contract on actions, it makes no difference whether or not they can contract on outcomes. This is because the lender can accomplish the internal risk sharing through the contract even if they cannot, as discussed below.

${ }^{10}$ For example, to enforce $\left(e_{x}, e_{y}\right)$, the transfer function could be set $t\left(e_{x}, e_{y}\right)=0 ; t\left(e^{\prime}, e_{y}\right)=B$ for $e^{\prime} \neq e_{x}$; $t\left(e_{x}, e^{\prime \prime}\right)=-B$ for $e^{\prime \prime} \neq e_{y}$; and $t\left(e^{\prime}, e^{\prime \prime}\right)=0$ for $e^{\prime} \neq e_{x}$ and $e^{\prime \prime} \neq e_{y}$. For $B$ large enough, $\left(e_{x}, e_{y}\right)$ is a Nash equilibrium. 
As before, the principal can be thought to be choosing $\boldsymbol{\kappa}$ to maximize total surplus, constrained however by what the group is doing:

$$
\begin{gathered}
\max e_{1}+e_{2}-C_{1}\left(e_{1}\right)-C_{2}\left(e_{2}\right)-1 / 2 r_{1}\left(\boldsymbol{\kappa}_{1}-\boldsymbol{\gamma}\right)^{T} \boldsymbol{\Sigma}\left(\boldsymbol{\kappa}_{1}-\boldsymbol{\gamma}\right)-1 / 2 r_{2}\left(\boldsymbol{\kappa}_{2}+\boldsymbol{\gamma}\right)^{T} \boldsymbol{\Sigma}\left(\boldsymbol{\kappa}_{2}+\boldsymbol{\gamma}\right) \\
\text { subject to: }(\boldsymbol{e}, \boldsymbol{\gamma}) \text { solves }(2) \text { given } \boldsymbol{\kappa} .
\end{gathered}
$$

It is shown in HM and earlier work that the lender's optimal design coincides with that for a single ("syndicate") borrower whose cost function satisfies $C\left(e_{1}, e_{2}\right)=C_{1}\left(e_{1}\right)+C_{2}\left(e_{2}\right)$ and absolute risk aversion $r$ satisfies $1 / r=1 / r_{1}+1 / r_{2}$. This corresponds to a lower cost to the pair of bearing risk, due to internal risk sharing. ${ }^{1112}$ Now the principal is reduced from four degrees of freedom or parameters to two, since what matters is not $\boldsymbol{\kappa}_{1}$ and $\boldsymbol{\kappa}_{2}$ individually, but the sum $\boldsymbol{\kappa}_{1}+\boldsymbol{\kappa}_{2}$. So, without loss of generality, assume $\kappa_{12}=\kappa_{21}=0 .{ }^{13}$ Given $\left(\kappa_{11}, \kappa_{22}\right)$, the total risk cost is

$$
(1 / 2) r\left[\kappa_{11}^{2} \sigma_{1}^{2}+\kappa_{22}^{2} \sigma_{2}^{2}+2 \kappa_{11} \kappa_{22} \rho \sigma_{1} \sigma_{2}\right]
$$

increasing in $\rho$.

Inspection of expression 2 also gives that here, as in the relative performance regime, actions will be chosen that equate $\kappa_{i i}$ and $C_{i}^{\prime}\left(e_{i}\right)$. Thus any pair of actions $\left(e_{1}, e_{2}\right)$ must be implemented by the same contract parameters $\left(\kappa_{11}, \kappa_{22}\right)$ in both regimes. This enables us to determine easily which regime delivers higher total surplus when implementing a given set of actions. For a given set of actions, the only part of total surplus that varies by regime is the risk cost, given in expressions 1 and 3, respectively; and these risk costs are easily compared, for a given set of actions, since $\left(\kappa_{11}, \kappa_{22}\right)$ are the same in both regimes.

It can be checked, using expressions 1 and 3, that at $\rho=0$ the risk cost of implementing any set of actions $\boldsymbol{e}$ is lower under the cooperative regime. ${ }^{14}$ It follows that at $\rho=0$, the cooperative regime gives higher total surplus than the individualistic regime. Similarly, at $\rho=1$ the risk cost of implementing any set of actions $\boldsymbol{e}$ is lower under the individualistic regime, and thus the individualistic regime gives higher total surplus. Further, as $\rho$ increases, the cost of implementing every set of actions in the cooperative regime is increasing (see expression 3), which implies that maximized surplus under this regime is decreasing in $\rho$. The

\footnotetext{
${ }^{11}$ As mentioned in a previous footnote, this result obtains whether or not the borrowers can themselves contract on output realizations. If they can contract on output, this ability will lead them to set $\gamma$ optimally to minimize the risk cost, without affecting incentives for actions. Now, if the pair does not have this ability, then note that principal can build the same insurance into the contract without affecting incentives. In particular, if $\left(\boldsymbol{\kappa}_{1}^{*}, \boldsymbol{\kappa}_{2}^{*}\right)$ and $\boldsymbol{\gamma}^{*}$ are optimal in the case where the group can contract on output, then the contract parameters $\left(\boldsymbol{\kappa}_{1}^{*}-\boldsymbol{\gamma}^{*}, \boldsymbol{\kappa}_{2}^{*}+\boldsymbol{\gamma}^{*}\right)$ produce the same outcome in the case where the group cannot contract on output: the risk cost is the same, and the incentives are also the same since $\boldsymbol{\kappa}_{1}^{*}+\boldsymbol{\kappa}_{2}^{*}=\boldsymbol{\kappa}_{1}^{*}-\boldsymbol{\gamma}^{*}+\boldsymbol{\kappa}_{2}^{*}+\boldsymbol{\gamma}^{*}$. In other words, since the group can coordinate on actions, only the sums of contract parameters (i.e. $\left.\kappa_{1 i}+\kappa_{2 i}\right)$ matter for incentives; this leaves the principal free to adjust the components of the sums to provide intragroup insurance, even if the group members themselves are unable to.

${ }^{12}$ It is assumed that there is no mechanism available for the lender to elicit borrower revelation of each others actions (information that each borrower is now assumed to know about the other). The agents can side-contract, so any such mechanism would have to be collusion-proof.

${ }^{13}$ Fix an optimal contract $\left(\boldsymbol{\kappa}_{1}, \boldsymbol{\kappa}_{2}\right)$ and optimal risk-sharing agreement $\boldsymbol{\gamma}$ and effort selection $\boldsymbol{e}$. Observe that $\boldsymbol{\kappa}_{1}^{\prime}=\left[\kappa_{11}+\kappa_{21}, 0\right]^{T}, \boldsymbol{\kappa}_{2}^{\prime}=\left[0, \kappa_{12}+\kappa_{22}\right]^{T}, \boldsymbol{e}^{\prime}=\boldsymbol{e}$, and $\boldsymbol{\gamma}^{\prime}=\left[\gamma_{1}+\kappa_{21}, \gamma_{2}-\kappa_{12}\right]^{T}$ give the same surplus and satisfy the same constraints. This contract must therefore also be optimal.

${ }^{14}$ This follows from the fact that $r=r_{1} r_{2} /\left(r_{1}+r_{2}\right)<r_{1}, r_{2}$.
} 
cost of implementing every set of actions in the individualistic regime is strictly decreasing in $\rho$ (see expression 3), which implies that the maximized surplus under this regime is strictly increasing in $\rho$.

In summary, holding risk aversion and other parameters constant, the payoff to the lender is strictly increasing in $\rho$ under relative performance and decreasing in $\rho$ under cooperation; and at $\rho=0$, the cooperative regime dominates, while at $\rho=1$, the relative performance regime dominates. This proves that there is a cutoff, $\bar{\rho} \in(0,1)$, above which the individualistic regime dominates and below which the cooperative regime does. The intuition is that when correlation is high, the scope for internal risk-sharing is low, while the lender is able to offer significant insurance through relative performance comparisons; and vice versa for low correlation. ${ }^{15}$

\subsection{Moral Hazard and Levels and Distribution of Wealth}

E. S. Prescott and Townsend (2002), PT, offer an extended version of HM in which wealth levels and distribution also affect regime optimality. The model still features unobserved, costly effort and analyzes a Pareto problem with a principal and two agents.

Cooperation or joint liability is again compared with non-cooperative or individual loans. The two regimes are compared in terms of their respective Pareto frontiers. In the cooperative regime, agents can internally enforce any set of actions and commit to a set of internal Pareto weights, according to which they will divide effort and consumption. In the individualistic regime, transfers and coordination on actions are disallowed.

There are two agents and two technologies, indexed by $i$ and $j$, respectively. The effort agent $i$ exerts on technology $j$ is $e_{i j}$. A special case would be $e_{i j}=0$ for $i \neq j$, so agent $i$ works only his own project. Total effort exerted by agent $i$ is $e_{i} \equiv e_{i 1}+e_{i 2}$. Define $a_{j}$ as the total effort exerted on technology $\mathrm{j} ; a_{j} \equiv e_{1 j}+e_{2 j}$. Let $q_{j}$ be the output from technology $j$. Finally, define vectors $\boldsymbol{c} \equiv\left[c_{1}, c_{2}\right]^{T}, \boldsymbol{q} \equiv\left[q_{1}, q_{2}\right]^{T}, \boldsymbol{a} \equiv\left[a_{1}, a_{2}\right]^{T}$ and $\boldsymbol{e}_{\boldsymbol{i}}$. $\equiv\left[e_{i 1}, e_{i 2}\right]^{T}$.

Agent $i$ maximizes utility $U_{i}\left(c_{i}\right)+V_{i}\left(T_{i}-e_{i}\right)$, defined over consumption $c_{i}$ and leisure, which equals total time endowment $T_{i}$ minus total effort. As in HM, varying degrees of risk aversion and work disutility could be allowed, but here utility is not generally transferable and preferences of the agents do not aggregate. The principal's payoff is $W\left(q_{1}+q_{2}-c_{1}-c_{2}\right)$, a special case of which is linear as in HM. Technology is expressed as a probability mass function $p(\boldsymbol{q} \mid \boldsymbol{a})$, and again, this can be parameterized and allows heterogeneity.

The Pareto problem to determine the information-constrained optimal allocation for each

\footnotetext{
${ }^{15} \mathrm{HM}$ and this exposition restrict attention to non-negative $\rho$. For $\rho$ in the negative range, the comparison is likely to reverse again at some point in the neighborhood of $\rho=-1$. To see this, note from expression 1 that a high correlation in absolute value is what makes the relative performance regime effective. In fact, for $\rho=-1,1$, borrowers bear no risk even under first-best incentives $\left(\kappa_{i i}=1\right)$. But note from expression 3 that the cooperative regime is also getting better at bearing risk as $\rho \rightarrow-1$. Clearly more negative correlation increases the scope for internal risk-sharing. But note that at $\rho=-1$ and $\kappa_{i i}=1$, the risk cost in the cooperative regime equals $1 / 2 r\left(\sigma_{1}-\sigma_{2}\right)^{2}$. Thus unless both agents have the same variance of output, the group still bears positive risk. (This is because the group still faces aggregate risk under perfect negative correlation, unless both members have the same variance.)

So in general, for $\rho$ in the neighborhood of negative one, the relative performance regime begins to dominate again. We restrict attention to HM's result on $\rho \in[0,1]$. In the context of mainly agricultural, rural borrowers, it is hard to imagine significant negative correlation between individual farmers.
} 
regime consists of maximizing a $\lambda$-weighted average of the borrowers' utilities, subject to the lender's expected utility reaching at least $\bar{W}$ and the appropriate incentive constraints. Suppose for simplicity that each of $c_{i}, q_{j}$, and $e_{i j}$ can take on a finite number of values. In the individualistic case, the credit contract induces individuals' effort $\boldsymbol{e}_{\boldsymbol{i}}$. and specifies individualized consumption amounts $\boldsymbol{c}$ as a function of output $\boldsymbol{q} \cdot{ }^{16}$ Linearity in compensation is not imposed however, and further, randomness in consumption is allowed. Even the contract itself can be randomized ex ante, inducing a random choice of effort. The more general notation is thus a lottery over all objects: $\Pi\left(\boldsymbol{c}, \boldsymbol{q}, \boldsymbol{e}_{\mathbf{1}}, \boldsymbol{e}_{\mathbf{2}}.\right)$. However, the optimal contract may often involve non-random effort recommendations and consumption allocations.

The more general contract must satisfy probability measure constraints

$$
\Pi\left(c, q, e_{1 .}, e_{2}\right) \geq 0, \quad \forall c, q, e_{1 .}, e_{2}
$$

and

$$
\sum_{\boldsymbol{c}, \boldsymbol{q}, \boldsymbol{e}_{1 .}, \boldsymbol{e}_{2}} \Pi\left(\boldsymbol{c}, \boldsymbol{q}, \boldsymbol{e}_{1 .}, \boldsymbol{e}_{2} .\right)=1
$$

The optimal contract is found by maximizing

$$
\sum_{\boldsymbol{c}, \boldsymbol{q}, \boldsymbol{e}_{\mathbf{1} .}, \boldsymbol{e}_{\mathbf{2}}} \Pi\left(\boldsymbol{c}, \boldsymbol{q}, \boldsymbol{e}_{\mathbf{1} .}, \boldsymbol{e}_{\mathbf{2}} .\right) \sum_{i} \lambda_{i}\left[U_{i}\left(c_{i}\right)+V_{i}\left(T_{i}-e_{i}\right)\right]
$$

subject to:

$$
\begin{aligned}
& \sum_{\boldsymbol{c}, \boldsymbol{q}, \boldsymbol{e}_{\mathbf{1} .,}, \boldsymbol{e}_{\mathbf{2}} .} \Pi\left(\boldsymbol{c}, \boldsymbol{q}, \boldsymbol{e}_{\mathbf{1} .}, \boldsymbol{e}_{\mathbf{2}} .\right) W\left(q_{1}+q_{2}-c_{1}-c_{2}\right) \geq \bar{W}
\end{aligned}
$$

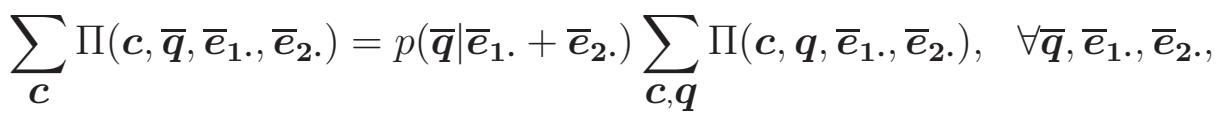

and

$$
\begin{aligned}
& \sum_{\boldsymbol{c}, \boldsymbol{q}, \boldsymbol{e}_{\mathbf{2}} .} \Pi\left(\boldsymbol{c}, \boldsymbol{q}, \boldsymbol{e}_{\mathbf{1}}, \boldsymbol{e}_{\mathbf{2}} \cdot\right)\left[U_{1}\left(c_{1}\right)+V_{1}\left(T_{1}-e_{1}\right)\right] \geq \\
& \sum_{\boldsymbol{c}, \boldsymbol{q}, \boldsymbol{e}_{\mathbf{2}} .} \Pi\left(\boldsymbol{c}, \boldsymbol{q}, \boldsymbol{e}_{\mathbf{1} .}, \boldsymbol{e}_{\mathbf{2}} .\right) \frac{p\left(\boldsymbol{q} \mid \hat{\boldsymbol{e}}_{\mathbf{1}}+\boldsymbol{e}_{\mathbf{2}}\right)}{p\left(\boldsymbol{q} \mid \boldsymbol{e}_{\mathbf{1}}+\boldsymbol{e}_{\mathbf{2}}\right)}\left[U_{1}\left(c_{1}\right)+V_{1}\left(T_{1}-\hat{e}_{1}\right)\right], \forall \boldsymbol{e}_{\mathbf{1} .}, \hat{\boldsymbol{e}}_{\mathbf{1}},
\end{aligned}
$$

and an incentive constraint for agent 2 similar to the last inequality. The first constraint ensures a given amount of resource extraction (possibly negative) from the pair. Note that as $\bar{W}$, the lender's expected receipts, increases, in effect the wealth of the borrower decreases. The second ensures that the mechanism assigns technologically feasible probabilities, and the last is an incentive constraint ensuring agent 1 abides by his recommended effort allocation.

In the cooperative, joint liability case, the borrowers are able to side contract. Thus they can internally enforce any set of (Pareto optimal) actions, conditional on the borrowing contract offered by the lender. They are also free to share risk internally by committing to ex post transfers as in HM. This means that the contract cannot specify the $c_{i}$ 's separately, only total group consumption, $c_{g} \equiv c_{1}+c_{2}$. Similarly, it cannot specify the individual effort choices

\footnotetext{
${ }^{16}$ As in HM, loan size could be made to vary, but is regarded as fixed and dropped from the notation.
} 
$\left(\boldsymbol{e}_{\mathbf{1}}, \boldsymbol{e}_{\mathbf{2}}\right.$.) separately, only the total effort on each technology, the $a_{j}$ 's. Given preferences that are separable in consumption and leisure, the actual consumption of agent $i$ can be expressed as a function of total consumption and the internal pareto weights, $c_{i}\left(c_{g}, \mu\right)$, where $\mu$ is the weight on agent 1, say. Similarly, effort of agent $i$ can be expressed as a function of total effort on each technology and the internal pareto weights, $e_{i}(\boldsymbol{a}, \mu) \cdot{ }^{17}$

The joint liability contract here takes the form $\Pi\left(c_{g}, \boldsymbol{q}, \boldsymbol{a}, \mu\right)$ and must satisfy similar probability measure constraints as above. It should also maximize

$$
\sum_{c_{g}, \boldsymbol{q}, \boldsymbol{a}, \mu} \Pi\left(c_{g}, \boldsymbol{q}, \boldsymbol{a}, \mu\right) \sum_{i} \lambda_{i}\left[U_{i}\left(c_{i}\left(c_{g}, \mu\right)\right)+V_{i}\left(T_{i}-e_{i}(\boldsymbol{a}, \mu)\right)\right]
$$

subject to:

$$
\begin{gathered}
\sum_{c_{g}, \boldsymbol{q}, \boldsymbol{a}, \mu} \Pi\left(c_{g}, \boldsymbol{q}, \boldsymbol{a}, \mu\right) W\left(q_{1}+q_{2}-c_{g}\right) \geq \bar{W} \\
\sum_{c_{g}} \Pi\left(c_{g}, \overline{\boldsymbol{q}}, \overline{\boldsymbol{a}}, \bar{\mu}\right)=p(\overline{\boldsymbol{q}} \mid \overline{\boldsymbol{a}}) \sum_{c_{g}, \boldsymbol{q}} \Pi\left(c_{g}, \boldsymbol{q}, \overline{\boldsymbol{a}}, \bar{\mu}\right), \quad \forall \overline{\boldsymbol{q}}, \overline{\boldsymbol{a}}, \bar{\mu}
\end{gathered}
$$

and

$$
\begin{aligned}
\sum_{c_{g}, \boldsymbol{q}} \Pi\left(c_{g}, \boldsymbol{q}, \boldsymbol{a}, \mu\right) \sum_{i} \mu_{i}\left[U_{i}\left(c_{i}\left(c_{g}, \mu\right)\right)+V_{i}\left(T_{i}-e_{i}(\boldsymbol{a}, \mu)\right)\right] \geq \\
\sum_{c_{g}, \boldsymbol{q}} \Pi\left(c_{g}, \boldsymbol{q}, \boldsymbol{a}, \mu\right) \frac{p(\boldsymbol{q} \mid \hat{\boldsymbol{a}})}{p(\boldsymbol{q} \mid \boldsymbol{a})} \sum_{i} \mu_{i}\left[U_{i}\left(c_{i}\left(c_{g}, \mu\right)\right)+V_{i}\left(T_{i}-e_{i}(\hat{\boldsymbol{a}}, \mu)\right)\right] \forall \boldsymbol{a}, \hat{\boldsymbol{a}}, \mu .
\end{aligned}
$$

There is a single group incentive constraint in this case: only joint deviations in effort are considered since the group can internally commit to a set of actions.

As has been pointed out, the setup of PT is similar to that of HM of section 2.1, but more general in several dimensions. This generality necessitates computation in order to characterize the solution, and in particular, how the optimal regime varies with $\bar{W}$ and the $\lambda_{i}$ 's. Attention in the simulations was restricted to the case in which each agent must work his own technology (that is, $e_{i j} \equiv 0, i \neq j$ ) and there is some positive correlation across technologies. Each agent also was given symmetric utility, endowment, and technological parameters.

The simulations indicate that the cooperative regime dominates for highly asymmetric $\lambda_{i}$ 's, no matter what $\bar{W}$ is. The cooperative regime is relatively better at extracting wealth from the low-weight agent and giving it to the high-weight agent. The low-weight agent in the group can be forced to work hard without incentive problems, due to the commitment ability within the group. For more symmetric $\lambda_{i}$ 's, the relative performance regime can dominate, but this is highly dependent on $\bar{W}$. For $\bar{W}$ low enough, it strictly dominates nowhere; the cooperative is always optimal. As $\bar{W}$ increases, the (symmetric) range around $\lambda_{1}=1 / 2,{ }^{18}$ for which the non-cooperative regime dominates increases up to a certain point, making individual loans more likely. For further increases in $\bar{W}$, as the group becomes

\footnotetext{
${ }^{17}$ If effort is not reallocable across technologies, that is agent 1 is tied to technology 1 and similarly for agent 2 , then $e_{i}(\boldsymbol{a}, \mu)=a_{i}$. If effort is reallocable, then $e_{i}(\boldsymbol{a}, \mu)=e_{i}\left(e_{g}, \mu\right)$, where $e_{g}=a_{1}+a_{2}$.

${ }^{18}$ We normalize the sum $\lambda_{1}+\lambda_{2}$ to one.
} 
poorer, the (symmetric) range around $\lambda_{1}=1 / 2$ for which the relative performance regime dominates diminishes, making the group regime attractive over a wider range. ${ }^{19}$

In a decentralization of this model, the payoff to the lender, $\bar{W}$, would vary inversely with the wealth of the borrowers, and the asymmetry of the $\lambda_{i}$ 's would reflect wealth dispersion among the borrowers. These simulations thus suggest that we should expect to see the cooperative regime occurring more frequently at higher levels of wealth inequality within a group. Controlling for inequality, we should expect to see the cooperative regime varying negatively with wealth when wealth is low and positively when it is high. This is a U-shaped relationship of the cooperative regime prevalence with group wealth.

\subsection{Adverse Selection and Technological Correlation}

Ghatak (1999) provides an adverse selection model of joint liability borrowing. Here the internal information is on the risk-type. The key choices of the agent in this model are the partner to join with in borrowing, and whether or not to borrow at all. Joint liability is shown to take advantage of the information borrowers have about each other in a way that enables decreasing the interest rate and drawing in safer borrowers, thus mitigating the adverse selection problem.

Regarding the choice of the borrowing partner of the agent, Ghatak shows that agents form groups that are homogeneous in risk-type. Regarding the choice about whether or not to borrow, the model delivers a cutoff risk-type, $\hat{p}$, such that all borrowers more risky than $\hat{p}$ borrow, and others do not. The latter prediction is our focus here.

A continuum of borrowers is assumed, each one with an exogenously given project indexed by a risk-type, $p$. This is the key heterogeneity. There is a density $g(p)>0$ of borrowers at each type $p \in[p, 1]$, where $p$ is a parameter of the model. The project of a borrower of type $p$ yields output $q(p)$ with probability $p$ and gives zero output otherwise. Ghatak also assumes that

$$
p q(p)=E, \quad \forall p \in[\underline{p}, 1] .
$$

Hence the borrowers do not differ in expected output. The only heterogeneity is in the second moment of this simple distribution, and one can verify that a lower $p$ implies higher risk, i.e. variance.

Borrowers are taken to be risk-neutral, unlike the previous models. It is assumed that one unit each of capital and labor are required to carry out the project. Each potential borrower is endowed with one unit of labor, which could be used by itself to produce $\underline{u}$, and no capital. Capital is available from a lender who offers borrowers take-it-or-leave-it contracts. Again, loan size could be introduced into the current notation, but as in the other models, we suppress it here.

\footnotetext{
${ }^{19}$ The intuition for the group regime's wider range of dominance at high or low levels of $\bar{W}$ seems to be as follows. For $\bar{W}$ low enough, the agents are not required to exert much effort. Both regimes are equally good when providing incentives for effort is not critical and redistribution is unimportant. Thus both are equally good at symmetric $\lambda_{i}$ 's, whereas for asymmetric $\lambda_{i}$ 's, the group regime dominates due to its advantage at redistributing wealth among the agents. For $\bar{W}$ high, the key is extracting wealth from the group. It appears the group regime is better at this because of internal commitment, while the relative performance regime requires more high-powered incentives, i.e consumption rewards, to induce high effort. It is unclear how robust this latter result is.
} 
The lender is assumed to observe only whether each project has succeeded or failed; thus the lender can contract on the binary outcome of success or failure, but not on the amount of output or risk-type, which would be optimal if these were observable. ${ }^{20}$ This implies that, in contrast to HM and PT, borrower payoff cannot depend on the borrowing pair's output other than through two binary functions, that is, depending only on whether each borrower realized returns greater than zero.

Ghatak focuses the analysis on groups of size two. A borrower of type $p$ who pairs with one of type $p^{\prime}$ has expected payoff of

$$
E-p r-p\left(1-p^{\prime}\right) l
$$

where $r>0$ is the interest rate and $l>0$ the joint liability payment. The interest rate is paid whenever the borrower succeeds and the joint liability payment whenever the borrower succeeds and his partner does not. By inspection, the cross-partial of the payoff with respect to $p$ and $p^{\prime}$ is $l>0$. This is sufficient to give that borrowers will match homogeneously in risk-type, as Ghatak shows. ${ }^{21}$

Homogeneous matching means the payoff of a borrower of type $p$ will be the following in equilibrium:

$$
E-p r-p(1-p) l \text {. }
$$

Note that the derivative of the payoff with respect to $p$ is $-[r+l(1-2 p)]$. As long as $l \leq r$, which we assume, this derivative is strictly negative for $p \in[p, 1)$. Thus, the safer an agent's type, the lower his payoff from borrowing and undertaking the project. Since all agents have an outside option that pays $\underline{u}$, agents will borrow if and only if the payoff from borrowing is greater than $\underline{u}$. Given that the payoff of borrowing is declining in $p$, there exists a cutoff risk-type, call it $\hat{p}$, such that borrowers of type $p>\hat{p}$ will not find it optimal to borrow, and borrowers of type $p<\hat{p}$ will borrow. ${ }^{2223}$ This prediction of adverse selection in a limited liability credit market is general and can be found in the literature at least as far back as

\footnotetext{
${ }^{20}$ Clearly, if type were observable, the lender could tailor the interest rate to each borrower's likelihood of success and eliminate the adverse selection problem. If output $q(p)$ were observable, this would be equivalent to knowing the borrower's type in this model, since $p=E / q(p)$ (and $E$ would presumably be known if there were many borrowers). This would then reduce to the case where type is observable and the lender can perfectly price discriminate.

The assumption of unobservable output in Ghatak distinguishes it from HM and PT, where the lender does observe output. It is likely, however, that the same qualitative results could be obtained in Ghatak even under observable output, provided certain modifications to the output distributions were made, including that the support of the output distributions did not vary by type.

${ }^{21}$ Intuitively, safe borrowers benefit relatively more from safe partners. This is because safe borrowers succeed more often, and are thus in the position of having a delinquent partner affect their payoff more often.

${ }^{22}$ This prediction is true ceteris paribus. If other characteristics, such as the outside option or expected return, vary across the borrowers, then of course $\hat{p}$ varies also. We control for varying $E$ and $\underline{u}$ using observable demographic, capital and occupational choice variables. Controlling for $r$ is of less concern in our data, since BAAC national policy at the time of the survey dictated charging a fixed interest rate of $9 \%$ on loans under sixty thousand Thai baht; the group loan ceiling was below this.

${ }^{23}$ Ghatak provides conditions under which joint liability will completely eliminate adverse selection (so that $\hat{p}=1$ ) and under which it will reduce but not eliminate the adverse selection problem ( $\operatorname{so}$ that $\hat{p}<1)$. Our test will only be valid for an interior cutoff (i.e. $\hat{p}<1$ ) and thus could in theory fail if joint liability has eliminated the adverse selection problem.
} 
Theorem 1 in Stiglitz and Weiss (1981). Again, it should be noted that the adverse selection here is in the riskiness, not means, of project outcomes.

Next we modify the model beyond Ghatak's work to consider correlation of output between borrowers, in the spirit of HM. There is a unique way to introduce correlation that preserves the same individual probabilities of success, for a given pair of borrowers, $\left(p, p^{\prime}\right)$. It is displayed in the following table:

\begin{tabular}{|l|c|c|}
\hline & 2 Succeeds $\left(p^{\prime}\right)$ & 2 Fails $\left(1-p^{\prime}\right)$ \\
\hline 1 Succeeds $(p)$ & $p p^{\prime}+\epsilon$ & $p\left(1-p^{\prime}\right)-\epsilon$ \\
\cline { 2 - 3 } 1 Fails $(1-p)$ & $(1-p) p^{\prime}-\epsilon$ & $(1-p)\left(1-p^{\prime}\right)+\epsilon$ \\
\hline
\end{tabular}

By inspection, each row and column adds to the correct individual probability of success or failure. Of course $\epsilon=0$ is the zero-correlation case, while $\epsilon>0$ introduces positive correlation. ${ }^{24}$ The above is the unique joint distribution, given a $\left(p, p^{\prime}\right)$ pair of individual probabilities. However, there are many $\left(p, p^{\prime}\right)$ combinations, and each could in theory have its own $\epsilon: \epsilon\left(p, p^{\prime}\right)$.

We consider two natural forms for the function $\epsilon\left(p, p^{\prime}\right)$, both of which give some uniformity to the correlation structure across all project pairings. First we may assume $\epsilon\left(p, p^{\prime}\right)$ to be constant: ${ }^{25}$

$$
\epsilon\left(p, p^{\prime}\right)=\epsilon, \forall p, p^{\prime}
$$

The second assumption, ${ }^{26}$

$$
\epsilon\left(p, p^{\prime}\right)=\tilde{\rho} * \min \left\{p^{\prime}(1-p), p\left(1-p^{\prime}\right)\right\}
$$

gives any homogeneous group the same correlation coefficient over project returns, equal to $\tilde{\rho}$, as a straightforward calculation shows. For non-homogeneous groups, that is those for whom $p \neq p^{\prime}, \tilde{\rho}$ is not the correlation coefficient, but something closely related: it is the correlation, expressed as a fraction of the maximum correlation possible given individual probabilities of $p$ and $p^{\prime}{ }^{27}$ When $p=p^{\prime}$, the maximum possible correlation coefficient is one, so $\tilde{\rho}$ equals the correlation coefficient. This formulation is arguably the most general, being the unique way of affecting each potential group's (appropriately normalized) correlation coefficient symmetrically.

\footnotetext{
${ }^{24}$ As does the HM analysis, we restrict attention here to positive correlation.

${ }^{25}$ Note that $\epsilon$ is restricted in value by the need to keep each cell of the distribution matrix no less than zero and no greater than one. For the off-diagonal cells of the matrix to be positive, we need $\epsilon$ to be less than $p\left(1-p^{\prime}\right)$ and $p^{\prime}(1-p)$. As $p$ or $p^{\prime}$ approaches one, $\epsilon$ is forced to zero, which is not interesting. To avoid this problem, we can modify the support of risk-types innocuously to exclude those with probability of success near 1:

$$
\exists \bar{p} \in(\underline{p}, 1) \text {, such that } \forall p \in(\bar{p}, 1], g(p)=0 .
$$

This assumption merely changes the support from $[p, 1]$ to $[p, \bar{p}]$, ensuring that all borrowers face at least some uncertainty. One can verify that under this modified support, $\epsilon \leq p(1-\bar{p})$ is necessary (and sufficient if $\epsilon \geq 0)$ to ensure no cell in the distribution matrix of every possible $\left(p, p^{\prime}\right)$ pairing exceeds one or falls below zero.

${ }^{26}$ It is clear that under this second assumption, any $\tilde{\rho} \in[0,1]$ is allowable, that is, keeps each cell in the distribution matrix of every possible $\left(p, p^{\prime}\right)$ pairing from exceeding one or falling below zero.

${ }^{27}$ Note that for non-homogeneous groups, it is a theoretical impossibility to have perfect correlation; two binomial variables with different individual probabilities of success can never be perfectly correlated. The further apart are the two probabilities, the lower the maximum correlation possible. One can calculate that
} 
The first step in examining correlation is to determine how it affects the equilibrium homogeneous matching result, if at all. The forms of correlation expressed in 4 and 5 do not, as can be shown by verifying that the gain to a risky borrower from switching to a safe partner is less than the loss to a safe borrower from switching to a risky partner (for $\tilde{\rho}$ nonnegative, see Ahlin and Townsend 2002). Given that homogeneous matching still obtains, the borrower payoff under correlation now becomes

$$
E-p r-[p(1-p)-\epsilon(p, p)] l .
$$

The indifference equation that defines the cutoff type $\hat{p}^{28}$ under assumption 4 becomes

$$
E-\hat{p} r-[\hat{p}(1-\hat{p})-\epsilon] l=\underline{u},
$$

and under assumption 5,

$$
E-\hat{p} r-\hat{p}(1-\hat{p})(1-\tilde{\rho}) l=\underline{u} .
$$

By inspection, the left-hand sides of equations 6 and 7 are increasing in $\epsilon$ and $\tilde{\rho}$, respectively. That is, higher correlation raises the payoff of the indifferent borrower. Clearly, for higher $\epsilon, \hat{p}$ will also have to be higher (since the borrowing payoff is still decreasing in $p$ ) in order to bring down the payoff and keep it equal to $\underline{u}$; the same is true for higher $\tilde{\rho}^{29}$ Since $\hat{p}$ is higher, the mass of borrowers has increased, or in other words, the probability that an agent chosen at random will borrow has increased. Thus, ceteris paribus, a population among whom technological correlation is higher will have more agents choose to borrow as group members and a higher chance that any given agent borrows in a group.

This result that correlation makes the group borrowing contract more likely is the opposite from HM. The idea here comes from the property of the model that a positive payoff only occurs when the borrower is successful. Correlation shifts the weight in this state of the world toward the sub-state where the borrower's partner is successful, away from the sub-state where the borrower's partner fails. Thus it raises the payoff and draws in more borrowers. ${ }^{30}$

the maximum correlation coefficient across two projects $\left(p, p^{\prime}\right)$, call it $\bar{\rho}\left(p, p^{\prime}\right)$, is equal to

$$
\bar{\rho}\left(p, p^{\prime}\right)=\min \left\{\sqrt{\frac{p\left(1-p^{\prime}\right)}{p^{\prime}(1-p)}}, \sqrt{\frac{p^{\prime}(1-p)}{p\left(1-p^{\prime}\right)}}\right\} .
$$

Further, the correlation coefficient corresponding to the $\epsilon\left(p, p^{\prime}\right)$ of assumption 5 can be shown to equal $\tilde{\rho} * \bar{\rho}\left(p, p^{\prime}\right)$. Thus $\tilde{\rho}$ has the interpretation, described in the text, as the correlation expressed as a fraction of the maximum possible correlation, and it can vary freely from zero to one. Of course, it is clear from the formula that $\bar{\rho}(p, p)=1$, so for homogeneous groups, $\tilde{\rho}$ is just the correlation coefficient itself.

${ }^{28}$ This is true for interior $\hat{p}$.

${ }^{29}$ In other words, total differentiation of equations 6 and 7 , respectively, shows that $d \hat{p} / d \epsilon>0$ and $d \hat{p} / d \tilde{\rho}>0$.

${ }^{30}$ Note that these comparisons involve a fixed interest rate $r$ and liability payment $l$. If the lender perfectly observed the degree of correlation, it might vary $r$ and $l$ with the level of correlation, and our comparisons would not be valid. As noted earlier, however, BAAC national guidelines stipulated interest rates of $9 \%$ for loans under sixty thousand, which is above the group loan ceiling, so there is very little interest rate variation (perhaps only noise) in the data. In general, the process seems best viewed as a standard contract being offered to any willing borrowers. 


\section{Empirical Results}

\subsection{Empirical Strategy}

The predictions of HM and PT can be tested by relating the likelihood of the cooperative, group regime - vis a vis the relative performance, individual regime - to correlation and wealth distribution variables. In particular, HM predict the group regime to be less likely the higher is correlation between agents' output. PT predict the group regime to be more likely the more disparate the wealth levels within the group, and the more extreme the wealth level of the group relative to the lender. In other words, there is a U-shaped relationship of group wealth with the likelihood of the group regime.

To measure existence of the cooperative and relative performance regimes, we focus on borrowing contracts. The rural credit market is an a priori likely candidate for the existence of moral hazard, due to lack of collateral of many poor borrowers and unobservability of effort. There is also significant risk to be borne in these predominantly agricultural settings. Thus the tradeoff between group and individual contracts analyzed in theory is likely to be present in our data.

In the theory, the key difference between the individual and group regimes is whether the agents can collude and enforce internal agreements. In practice this ability seems hard to measure, though it may be proxied well by variables measuring sharing and cooperative activities in other spheres of life (see Ahlin and Townsend 2002). The point of the theory, however, is that the contract itself may build in encouragement or facilitation of such cooperation, or leave it conspicuously absent. In other words, the theory relies on the lender and/or borrowers being able to turn on or off the borrowers' ability to side-contract. It seems natural to interpret the formation of groups as such a facilitation of side-contracting. Groups have meetings together, are under a designated internal leader, and engage in significant internal monitoring. In our data, the average borrowing group (from the BAAC) has $70 \%$ of its members communicating with the group leader at least twice per week and $35 \%$ of its members at least six times per week.

Individual loans, on the other hand, can be thought of as the relative performance regime, though of course in reality the principal cannot enforce complete lack of cooperation between agents. He can, however, abstain from encouraging it. Further, the primary lender in our data, the BAAC, does seem to base its stringency toward one borrower in part on the performance of other borrowers, as discussed in the introduction. It is at least reasonable then to associate the relative performance regime in the theory with individual loans in the data.

Tying these two regimes to individual and group loans, respectively, we face the difficulty of drawing the boundary lines of the group empirically. In the theory, contracts always involve two agents. In practice, joint liability groups (of the BAAC) typically have between five and fifteen members, a small minority having between fifteen and thirty. Further, we do not observe in our data the group with whom each borrowing household is matched. It is even more difficult to determine the set of borrowers with whom an individual borrower is being compared in a relative performance regime; certainly there is no reason to expect that the comparison group contains just one other borrower, as in the theory. Our simplifying assumption in both cases is that the village forms the boundary from which the group can 
be drawn and among which comparisons are made for individual borrowers. The village is the smallest unit into which our data classify each borrower. It makes sense as a boundary for explicit borrowing groups: in our data, over $65 \%$ of such groups (of the BAAC) have all their membership from a single village, and over $90 \%$ have more than half. Since correlation is likely higher within a village than across villages, it is probably also the best choice of a relative performance comparison group. ${ }^{31}$

To summarize, the data we use are household-level observations that show whether the household is borrowing and under which regime, but do not allow us to determine explicitly group membership (whether the group is a comparison group under relative performance, or an explicit borrowing group under the cooperative regime). To measure ${ }^{32}$ wealth dispersion within the group, then, we use a measure of distance between the borrowing household's wealth and the village mean wealth. The assumption is that the further the household is away from the village mean, the higher the likelihood that it is in a group with asymmetric wealth. We measure correlation within the group by the degree of clustering of superlative years (for household income) of this household with other households in the village. Again, the assumption is that the more this household's good and bad years coincide with others in the village, the more likely the case that it is in a group with high correlation. Finally, to proxy the wealth of the group, we use different combinations of the wealth of the household itself and the village average wealth of borrowing households. Each of these two components has its advantage. The wealth of the household itself is certainly a component of group wealth, since we know for certain this household belongs to the borrowing group in question. However, the wealth of the remainder of the group is a more significant component of total group wealth, since groups contain multiple households; but using the village average wealth of borrowers measures wealth of the remainder of the group with error.

Ultimately, we use these measures of group wealth, wealth dispersion, and correlation, all at the household level, to explain whether the household has a group loan. Since the theory knows nothing of agents involved in both kinds of regimes or in neither, we exclude from the regression households with both kinds of loans or with neither. The results are detailed in section 3.3.

The Ghatak model focuses on risk-type and correlation as key determinants of whether a household will borrow. We use the same household-level correlation measure described in the preceding paragraphs, reflecting the coincidence of the household's good and bad years with other households in the village. The risk-type measure applies the theory directly to subjective evaluations the household makes about the distribution its future income prospects. This measure is detailed in section 3.2 .

The key decision, then, is what to do with households having individual loans, since the Ghatak theory does not leave room for them. ${ }^{33}$ One option is to exclude them, just

\footnotetext{
${ }^{31}$ One might argue under HM-type logic that forming cooperative groups out of borrowers from different villages would be optimal, since this would minimize correlation. However, the ability of such borrowers to monitor and enforce internal agreements would presumably be low, due to geographic separation and lack of contact. Thus a group contract between borrowers from different villages may be ruled out as highly costly a priori.

${ }^{32}$ Variable construction is discussed in more detail in section 3.2.

${ }^{33}$ The theory shows that joint liability contracts always produce more social surplus than individual liability contracts, though they may not be Pareto optimal in that they can hurt the risky borrowers in equilibrium.
} 
as households that did not fit into HM and PT theory were excluded in that specification. Another option is to include them and group them with households having group loans. The rationale for this would be that the key to the adverse selection result is not the form of liability, individual or joint, but rather whether liability is limited. ${ }^{34}$ Thus if the individual loans are limited liability, they too should exhibit adverse selection. In fact it is likely they are limited liability to some degree; as argued above, the collateral goes unseized not infrequently and provisions are sometimes made. However, even in this case, it may be that these loans are significantly closer to full liability than are joint liability loans. This would argue for their inclusion with non-borrowing households in the regression, since full liability makes risk-type unimportant. Further, the correlation result relies critically on both joint and limited liability, so this specification is clearly preferred on those grounds. Fortunately, the key results are insensitive to the differences in these specifications.

\subsection{Description of Variables}

Our data are taken from a detailed survey of households in Thailand conducted in 1997. The survey covers two contrasting regions in Thailand. The central region is relatively close to Bangkok and enjoys a degree of industrialization as well as fertile land for farming. The northeast region is poorer and semi-arid. There is significant wealth variation both within and across regions. Within regions, sampling was stratified based on ecological zones, to ensure variation in good and bad years. This stratification affected choices of sub-counties, or tambons. Within tambons, choices of villages and of households within villages were random. In all 192 villages were surveyed. In virtually all of these villages, fifteen households were surveyed, giving a total sample size of 2875. Table I gives a summary of all dependent and independent variables used, reporting means for all but squared terms and standard deviations for all but squared terms and dummy variables.

The dependent variables that we use are dummies reflecting whether the household has taken out a group-guaranteed loan from a lending institution in the past year. There are two versions of this variable. The first, BAGPLOAN, restricts attention to group-guaranteed loans from the BAAC. This government institution is the primary institutional lender in rural Thailand: for example, $64 \%$ of institutional loans in our sample are from the BAAC. The BAAC offers both individual loans, which much be guaranteed by some form of collateral, usually land, and joint liability loans. To receive the latter, one must form or join an official BAAC-registered borrowing group and enter into a joint liability arrangement. BAGPLOAN equals one if the household has had outstanding a loan from the BAAC in the past year and lists the collateral for this loan as either none, a single guarantor, or multiple guarantors. About $23 \%$ of the household sample has such a loan.

The second version of the dependent variable is GRUPLOAN, which incorporates groupguaranteed loans from the BAAC and other institutions. These others are typically smaller institutions such as agricultural cooperatives and often village-based ones such as production credit groups (PCGs), but they also include commercial banks. ${ }^{35}$ Using this broader definition increases the proportion of the sample that qualifies as having a group-guaranteed

\footnotetext{
${ }^{34}$ Stiglitz and Weiss (1981) get the same result in the context of individual, limited liability.

${ }^{35}$ Specifically, they include PCGs, commercial banks, agricultural cooperatives, village funds, rice banks, as well as any other cooperatives, institutions, or programs that also lend funds.
} 
Table I - Summary of Variables

\begin{tabular}{|c|c|c|c|}
\hline $\begin{array}{l}\text { Variable } \\
\end{array}$ & $\overline{\text { Description }}$ & Mean & $\overline{(\sigma)}$ \\
\hline \multicolumn{4}{|c|}{ DEPENDENT: } \\
\hline "BAGPLOAN & $\begin{array}{l}\text { Has the household obtained a BAAC group-guaranteed } \\
\text { loan in the past year? }\end{array}$ & 0.22 & \\
\hline GRUPLOAN & $\begin{array}{l}\text { Has the household obtained an institutional group- } \\
\text { guaranteed loan in the past year? }\end{array}$ & 0.29 & \\
\hline BAIDLOAN & $\begin{array}{l}\text { Has the household obtained a BAAC individual loan in } \\
\text { the past year? }\end{array}$ & 0.14 & \\
\hline INDLOAN & $\begin{array}{l}\text { Has the household obtained an institutional individual } \\
\text { loan in the past year? }\end{array}$ & 0.23 & \\
\hline \multicolumn{4}{|c|}{ INDEPENDENT: } \\
\hline \multicolumn{4}{|c|}{ Correlation: } \\
\hline SAMEBEST & $\begin{array}{l}\text { Percent of other village responses agreeing with this one } \\
\text { on best year }\end{array}$ & 0.30 & $(0.23)$ \\
\hline SAMEWRST & $\begin{array}{l}\text { Percent of other village responses agreeing with this one } \\
\text { on worst year }\end{array}$ & 0.28 & $(0.22)$ \\
\hline SAMEITHR & $\begin{array}{l}\text { Percent of other village responses agreeing with this one } \\
\text { on superlative year }\end{array}$ & 0.29 & $(0.17)$ \\
\hline \multicolumn{4}{|c|}{ Wealth: } \\
\hline WEALTH & Wealth of the household, in million baht & 1.8 & $(5.8)$ \\
\hline WEALTHSQ & Wealth squared, in million baht-squared & & \\
\hline WLTHDSPR & $\begin{array}{l}\text { Measure of distance from household wealth to village } \\
\text { mean wealth }\end{array}$ & 0.81 & $(0.39)$ \\
\hline TITLE & Wealth attributable to titled land, in million baht & 0.94 & $(5.0)$ \\
\hline TITLESQ & $\begin{array}{l}\text { Wealth attributable to titled land squared, in million } \\
\text { baht-squared }\end{array}$ & & \\
\hline \multicolumn{4}{|c|}{ Risk Type: } \\
\hline PROBHI & Probability of realizing high income next year & 0.57 & $(0.26)$ \\
\hline \multicolumn{4}{|c|}{ Control: } \\
\hline INCOME & $\begin{array}{l}\text { Gross household income from past year, in million } 1997 \\
\text { Thai baht }\end{array}$ & 0.15 & $(2.2)$ \\
\hline EXINCOME & $\begin{array}{l}\text { Expected household income for next year, in million } \\
\text { baht }\end{array}$ & 0.11 & $(0.30)$ \\
\hline NRTHEAST & Dummy $=1$ if the village is in the northeast region & 0.50 & \\
\hline AGRYES & $\begin{array}{l}\text { Does household engage in agriculture and want to ex- } \\
\text { pand operations? }\end{array}$ & 0.46 & \\
\hline AGRNO & $\begin{array}{l}\text { Does household engage in agriculture and not want to } \\
\text { expand operations? }\end{array}$ & 0.33 & \\
\hline OWNSBSNS & Does household own a business? & 0.21 & \\
\hline LANDOWND & Average landholdings (in rai) of household & 17.2 & $(30.4)$ \\
\hline EDYEARH & Years of education attained by head of household & 4.1 & $(2.6)$ \\
\hline MALEH & Is head of household male? & 0.77 & \\
\hline
\end{tabular}


loan to about $30 \% .{ }^{36}$ However, the institutions incorporated are diverse in size and practice, which makes isolating contracts that are clearly group contracts more imprecise. We report specifications using both BAGPLOAN and GRUPLOAN.

Two analogous variables measure whether the household has an individual loan contract from a lending institution. BAIDLOAN and INDLOAN correspond to BAGPLOAN and GRUPLOAN, respectively, in the lenders they cover. The criterion for a loan counting as an individual loan are that the collateral used was land, savings, current or future crops, and other collateral such as house or boat. ${ }^{37}$ BAIDLOAN is positive for about $13 \%$ of the population, INDLOAN for about $22 \%$. Neither of these will be used directly in regressions, but will at times be used to limit the sample to only those households having borrowed either an individual or a group loan.

Key independent variables from PT include WEALTH and its square, WEALTHSQ, measured in millions of 1997 Thai baht and millions of baht-squared, respectively. These count up all types of household wealth, including land, household assets, business assets, agricultural assets, and financial assets, including debts and savings. The part of this wealth attributable to landholdings to which the household has a legal title is called TITLE, and its square is TITLESQ. These measures are helpful as proxies for the value of available collateral, since titled land is the predominate form of collateral, at least with the BAAC. Recall that collateral plays no role in the theory.

To measure wealth dispersion WLTHDSPR, which corresponds to the $\lambda_{i}$ 's of PT, we use the following function of household wealth and village average wealth, call it $\overline{W E A L T H}$ :

$$
W L T H D S P R=\left|1-\frac{W E A L T H}{\overline{W E A L T H}}\right|^{1 / 2}
$$

This is similar to a simple distance function, $|\overline{W E A L T H}-W E A L T H|$. The differences are that we divide by $\overline{W E A L T H}$, which makes it a scale-free measure, ${ }^{38}$ and we take a square root which dampens the effect of WEALTH's long right tail. To check robustness relative to functional form, we will also use a nonparametric regression technique on $\frac{W E A L T H}{W E A L T H}$ itself.

Technological correlation $\rho$ is of course difficult to measure. Our proxy focuses on correlation of good and bad years of a household with the rest of their village. Each household was asked which of the past five years was best and which was worst, in terms of household income. (The wording of the question does seem to evoke income gross of any informal risk sharing, thus increasing our confidence that it is capturing technological variation in

\footnotetext{
${ }^{36}$ For all but the BAAC, we tighten the criterion for a loan from a given institution to qualify as groupguaranteed. It must list as collateral a single guarantor or multiple guarantors; listing the loan as requiring no collateral leads us to count the loan as indeterminate. The reason for our distinguishing between lenders in this way is our better knowledge of BAAC policy. They do not give loans to anyone without collateral unless they belong to a borrowing group, so those who list no collateral requirement almost certainly are referring to a group loan.

${ }^{37} \mathrm{~A}$ few loans for which the collateral was a relative's land or something undecipherable were counted as indeterminate. Loans effectively collateralized through some contract interlinkage, such as by future wages where the loan is from an employer, were categorized as neither group nor individual.

${ }^{38}$ In other words, WLTHDSPR does not change if the wealth of everyone in the village goes up or down by the same multiplicative factor. Since power utility is used in the computational results, and since the ratio of marginal utilities under power is scale-free, WLTHDSPR also should be scale-free.
} 
income.) SAMEBEST, SAMEWRST, and SAMEITHR, reflect the percent of the other village households' responses that coincide with this household's responses regarding the best year, worst year, and about either year, respectively. ${ }^{39}$ We use each of these measures. The theories we test do not give clear direction on which should be more helpful.

The final key variable to measure is the risk-type of the borrower. We do so using subjective income assessments, taking the Ghatak model quite literally. Specifically, each household was asked what their income would be in the coming year if it were a good year (Hi), what their income would be if it were a bad year (Lo), and what they expected their income to be $(\mathrm{Ex})$. We assume the income distribution is binomial over the high and low states, as in the Ghatak model. The probability of success, PROBHI, is then calculated to be

$$
P R O B H I=\frac{E x-L o}{H i-L o},
$$

using the fact that $P R O B H I * H i+(1-P R O B H I) * L o=E x$.

Several control variables are included, suggested by theory, institutional details, or practicality. We include next year's expected income (Ex), called EXINCOME, in our regressions. This is necessary because the Ghatak model assumes expected returns to be the same across all borrowers, while it of course varies in our data. We also include a comprehensive measure of income over the past twelve months, INCOME. ${ }^{40}$

The household head's gender and years of education are controlled for in MALEH (male coded as one) and EDYEARH, respectively. We also include a dummy variable, NRTHEAST, equaling one for the $50 \%$ of households in the poorer Northeast region. These are also important controls because the Ghatak model assumes the same outside (non-borrowing) option $\underline{u}$ for all borrowers, while outside options clearly vary in our data.

Finally, we control for eligibility and desire for a loan. Households were asked whether or not they engage in agricultural activity, and if so, whether or not they would like to expand their operations. From these questions we derive two dummy variables, AGRYES and AGRNO. AGRYES (AGRNO) equals one for the 46\% (33\%) of households that engage in agricultural activity and would (would not) like to expand their activity. The remaining $21 \%$ of households for whom neither equals one are those who do not engage in agricultural activity. It is crucial to control for occupation, since the BAAC and several other institutional lenders targeted agricultural workers exclusively at the time of the survey. One further proxy for desirability of a loan is the dummy variable OWNSBSNS, which equals one for the $21 \%$ of households that own a business. ${ }^{41}$

\subsection{Logit Results}

We use simple logits since the dependent variables, whether the household has a group loan, are dummies. We report twelve specifications, varying across the three measures of

\footnotetext{
${ }^{39}$ For example, if a household lists the same best year as 4 of 12 other village households and the same worst year as 7 of 14 other village respondents, then $S A M E B E S T=4 / 12, S A M E W R S T=7 / 14$, and $S A M E I T H R=11 / 26$. (Some households answer one question but not the other.)

${ }^{40}$ In some footnoted specifications we also control for the variance of next year's income, using the subjective income assessments described in the preceding paragraphs.

${ }^{41}$ It is purely coincidental that the same percent of households own businesses and do not engage in agriculture: there are households of whom both are true, and of whom neither are true.
} 
correlation, the two versions of the dependent variable, and the sample chosen, whether restricted or unrestricted. More specifically, the restricted sample includes only those households that have either a group-guaranteed BAAC (or institutional) loan, or an individual BAAC (or institutional) loan. That is, it includes only households for whom BAGPLOAN+ $B A I D L O A N=1$ (or GRUPLOAN+INDLOAN=1). The rationale for examining this restricted sample is that $\mathrm{HM}$ and $\mathrm{PT}$ focus on the choice between cooperative and relative performance regimes given that one must be chosen. Thus the restricted sample regressions, though smaller in amount of data, are arguably more appropriate tests of HM and PT.

The logit results are reported in tables II and III, for the restricted and entire samples, respectively. It should also be noted that in each regression, we exclude households who have not answered the questions about both best and worst years or whose village does not contain at least four responses to each of these questions. ${ }^{42}$

Table II is the preferred specification for testing HM and PT. In all specifications, wealth levels exhibit a U-shaped relationship with the group contract. These coefficients are all significant at the $5 \%$ significance level, except that under BCGPLOAN the coefficient on WEALTHSQ drops to the $10 \%$ significance level and under GRUPLOAN the coefficient on WEALTH drops to the $10 \%$ level. These baseline specifications give strong evidence for the wealth level predictions of PT.

The trough of the U-shaped relationship is around 6.4 million baht for BAGPLOAN and 8.4 million baht for GRUPLOAN. This leaves $5-6 \%$ of the sample on the upward sloping segment of the relationship. The U-shape remains significant under exclusion of households with wealth greater than 20 million (1.4\% of the data). ${ }^{43}$ We check a cubic relationship for robustness and find a very similar picture: coefficients on WEALTH and WEALTHSQ of the same sign as in Table II and significant at 1\%, and the coefficient on WEALTHCB negative and significant at $5 \%$ or $10 \%$ depending on specification. Further, the relationship is declining to a trough between 5 and 6 million baht, then increasing to a peak at just over 21 million, and declining from there (for just over 1\% of the data). Thus the U-shape over virtually all the data appears robust.

The same relationship is estimated using Yatchew's (1998) estimator. ${ }^{44}$ The results using both dependent variables (and SAMEITHR as the measure of correlation) are pictured in

\footnotetext{
${ }^{42} \mathrm{SAMEITHR}$ is valid in about $66 \%$ of households, after dropping households from villages where less than eight total responses to the two questions exist. SAMEBEST is valid in about $71 \%$ of households and SAMEWRST in about $80 \%$ of households, after dropping households from villages where less than four total responses to the respective question exist. For the regressions we report, we restrict each specification to the $66 \%$ of households that have valid information for both SAMEBEST and SAMEWRST. This ensures the sample is not changing as we use different measures of correlation. We have run the regressions using all the data available in each specification, and the results become somewhat different, but not enough to change our qualitative conclusions.

${ }^{43}$ It does disappear as this cutoff decreases to 10 million (3.4\% of the data); but this is not surprising since we are ignoring a significant fraction of households above the turning point.

${ }^{44}$ Specifically, a partially linear model is assumed where all the regressors but wealth affect the dependent variable linearly, while wealth can have any kind of smooth effect. Fifth-order optimal differencing is used to remove the effect of wealth and estimate the linear coefficients. The effect of all the variables but wealth is then substracted from the dependent variable to form a residual. Residuals are then demeaned, since we are not concerned with the intercept, and are put as the dependent variable in a locally linear regression with wealth as the predictor. We use a bandwidth to incorporate $80 \%$ of the data and the tri-cube weighting function (see Cleveland 1979 and Fan 1992) to downweight observations $w_{g}$, say, further from the current
} 


\section{Table II - Restricted Samples}

The samples are restricted only to those borrowers having either a group-guaranteed loan, or an individual loan.

Standard errors in parentheses; significance at 5, 10, and 15\% denoted by ***, **, and *, respectively.

\begin{tabular}{|c|c|c|c|c|c|c|}
\hline & \multicolumn{3}{|c|}{ BAGPLOAN } & \multicolumn{3}{|c|}{ GRUPLOAN } \\
\hline \multirow{2}{*}{ WEALTH } & -.417 & -.418 & -.418 & -.174 & -.173 & -.175 \\
\hline & $(.169)^{* * *}$ & $(.169)^{* * *}$ & $(.169)^{* * *}$ & $(.096)^{* *}$ & $(.097)^{* *}$ & $(.097)^{* *}$ \\
\hline \multirow{2}{*}{ WEALTHSQ } & $3.24 \mathrm{E}-8$ & $3.28 \mathrm{E}-8$ & $3.26 \mathrm{E}-8$ & $1.03 \mathrm{E}-8$ & $1.03 \mathrm{E}-8$ & $1.02 \mathrm{E}-8$ \\
\hline & $(1.73 \mathrm{E}-8)^{* *}$ & $(1.72 \mathrm{E}-8)^{* *}$ & $(1.73 \mathrm{E}-8)^{* *}$ & $(4.91 \mathrm{E}-9)^{* * *}$ & $(4.98 \mathrm{E}-9)^{* * *}$ & $(4.94 \mathrm{E}-9)^{* * *}$ \\
\hline \multirow{2}{*}{ WLTHDSPR } & .696 & .686 & .695 & .505 & .500 & .509 \\
\hline & $(.253)^{* * *}$ & $(.254)^{* * *}$ & $(.254)^{* * *}$ & $(.217)^{* * *}$ & $(.217)^{* * *}$ & $(.217)^{* * *}$ \\
\hline \multirow{2}{*}{ TITLE } & .213 & .219 & .216 & -.053 & -.043 & -.046 \\
\hline & $(.164)$ & $(.165)$ & $(.165)$ & $(.090)$ & $(.090)$ & $(.090)$ \\
\hline \multirow{2}{*}{ TITLESQ } & $-3.14 \mathrm{E}-8$ & $-3.21 \mathrm{E}-8$ & $-3.17 \mathrm{E}-8$ & $-8.14 \mathrm{E}-9$ & $-8.19 \mathrm{E}-9$ & $-8.10 \mathrm{E}-9$ \\
\hline & $(1.70 \mathrm{E}-8)^{* *}$ & $(1.70 \mathrm{E}-8)^{* *}$ & $(1.70 \mathrm{E}-8)^{* *}$ & $(4.63 \mathrm{E}-9)^{* *}$ & $(4.71 \mathrm{E}-9)^{* *}$ & $(4.66 \mathrm{E}-9)^{* *}$ \\
\hline \multirow{2}{*}{ PROBHI } & .023 & .017 & .029 & -.139 & -.124 & -.123 \\
\hline & $(.353)$ & $(.354)$ & $(.353)$ & $(.308)$ & $(.308)$ & $(.308)$ \\
\hline \multirow[t]{2}{*}{ SAMEBEST } & .176 & & & .549 & & \\
\hline & $(.401)$ & & & $(.350)^{*}$ & & \\
\hline \multirow{2}{*}{ SAMEWRST } & & -.190 & & & -.059 & \\
\hline & & $(.407)$ & & & $(.367)$ & \\
\hline \multirow{2}{*}{ SAMEITHR } & & & .009 & & & .482 \\
\hline & & & $(.513)$ & & & $(.471)$ \\
\hline \multirow{2}{*}{ INCOME } & .312 & .335 & .310 & .075 & .082 & .037 \\
\hline & $(.877)$ & $(.882)$ & $(.876)$ & $(.738)$ & $(.735)$ & $(.727)$ \\
\hline \multirow{2}{*}{ EXINCOME } & -.732 & -.771 & -.734 & -.090 & -.102 & -.042 \\
\hline & (1.10) & (1.11) & (1.10) & $(.943)$ & $(.938)$ & $(.928)$ \\
\hline \multirow{2}{*}{ NRTHEAST } & -.368 & -.344 & -.355 & -.223 & -.191 & -.222 \\
\hline & $(.214)^{* *}$ & $(.213)^{*}$ & $(.214)^{* *}$ & $(.176)$ & $(.176)$ & $(.177)$ \\
\hline \multirow{2}{*}{ AGRYES } & -.538 & -.537 & -.530 & .003 & .040 & .021 \\
\hline & $(.522)$ & $(.522)$ & $(.522)$ & $(.354)$ & $(.353)$ & $(.353)$ \\
\hline \multirow{2}{*}{ AGRNO } & -.804 & -.802 & -.798 & -.415 & -.387 & -.403 \\
\hline & $(.531)^{*}$ & $(.532)^{*}$ & $(.531)^{*}$ & $(.361)$ & $(.360)$ & $(.361)$ \\
\hline \multirow{2}{*}{ OWNSBSNS } & -.116 & -.125 & -.117 & -.512 & -.521 & -.508 \\
\hline & $(.225)$ & $(.226)$ & $(.226)$ & $(.189)^{* * *}$ & $(.189)^{* * *}$ & $(.189)^{* * *}$ \\
\hline \multirow{2}{*}{ LANDOWND } & $-7.28 \mathrm{E}-3$ & $-7.21 \mathrm{E}-3$ & $-7.25 \mathrm{E}-3$ & $-6.21 \mathrm{E}-3$ & $-6.22 \mathrm{E}-3$ & $-6.27 \mathrm{E}-3$ \\
\hline & $(4.12 \mathrm{E}-3)^{* *}$ & $(4.12 \mathrm{E}-3)^{* *}$ & $(4.11 \mathrm{E}-3)^{* *}$ & $(3.45 \mathrm{E}-3)^{* *}$ & $(3.45 \mathrm{E}-3)^{* *}$ & $(3.44 \mathrm{E}-3)^{* *}$ \\
\hline \multirow{2}{*}{ EDYEARH } & .030 & .029 & .030 & .010 & .007 & .010 \\
\hline & $(.042)$ & $(.042)$ & $(.042)$ & $(.033)$ & $(.033)$ & $(.033)$ \\
\hline \multirow{2}{*}{ MALEH } & .437 & .446 & .445 & .628 & .644 & .632 \\
\hline & $(.243)^{* *}$ & $(.243)^{* *}$ & $(.243)^{* *}$ & $(.208)^{* * *}$ & $(.208)^{* * *}$ & $(.208)^{* * *}$ \\
\hline$N$ & 573 & 573 & 573 & 736 & 736 & 736 \\
\hline
\end{tabular}


Figure 1, which depicts the relationships for wealth below twenty million baht. ${ }^{45}$ The Ushape is evident in the function estimates over almost all the data, though the upward-sloping part is less tightly estimated due to sparser data. At a minimum, it does appear that the logit U-shape results are not being driven by imposed quadratic or cubic curvature.
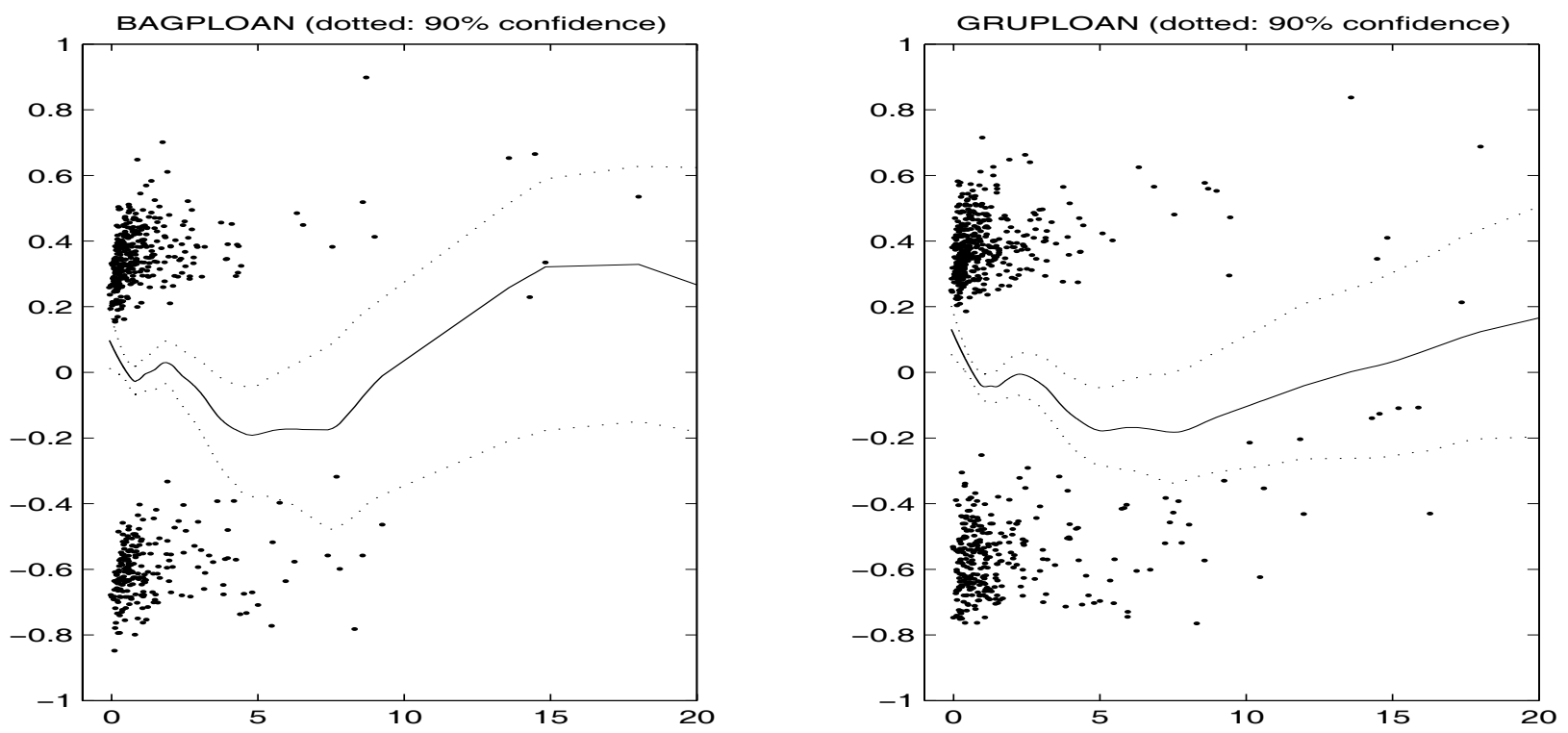

Figure 1: Wealth as a predictor of having a group loan.

There may be other explanations for such a relationship. Chief among these could be a story revolving around collateralizable wealth: since individual loans require collateral, we would expect them to be more prevalent at higher wealth levels, at the expense of group loans. This story, however, does not immediately make clear why the relationship should turn up again to deliver a U-shape. Further, we separate out and control for the part of wealth that is most commonly used and accepted as collateral, TITLE and TITLESQ, and still find the U-shaped relationship between total wealth and being in a group contract. Thus the collateral story does not seem to be driving the results. ${ }^{46}$

observation $w$ :

$$
\text { Weight }_{g}=\left(1-\left(\frac{\left|w-w_{g}\right|}{1.0001 h(w)}\right)^{3}\right)^{3} .
$$

Bootstrapped error bands are created by sampling with replacement from the original sample and repeating the same procedure, 1000 times; the error bands are then the 51st and 950th smallest estimates at each point.

${ }^{45}$ That is, the graph (not the actual procedure) leaves out the part of the curve from wealth of twenty million baht to one hundred million baht, to focus on the key part of the relationship. There are only five to ten data points about twenty million, so the error bands are quite wide above there.

${ }^{46}$ In fact, excluding TITLE and TITLESQ from the regression gives a much more linearly negative relationship between wealth and borrowing (i.e. the positive coefficients on WEALTHSQ drop in significance). Evidently, in that specification, WEALTH measures both collateral and wealth in the PT sense, and the more uniformly negative (or at least concave) effect of collateral is keeping the relationship with WEALTH from turning up to form a $\mathrm{U}$. 
One might also think that poor households borrow in groups, moderately wealthy households borrow as individuals, and the most wealthy households take out both kinds of loans since their demand for credit is higher. This would produce a U-shape relationship between wealth and having a group loan. But note that this explanation is ruled out since the sample includes households with one or the other kind of loan, but not both.

Of course, one caveat regarding these results is that we do not have group-level wealth, only wealth of households. Another approach would be to proxy group wealth for a given household as the average between that household's wealth and the average household wealth level in the village (or among villagers who borrow). The inverted-U shape loses significance in the majority of specifications under this approach. This need not be due to a deficiency of the model, but rather an imperfect proxy for group wealth. We continue to view the evidence presented in Table II as suggestive evidence for the model.

Also a strong and statistically significant result for the PT model is that group borrowing is more likely the higher is WLTHDSPR, that is, for those with wealth further away from the village average. Evidently the group contract is used more heavily for borrowers with asymmetric wealth. Thus the wealth inequality predictions of PT are also borne out. This result is even more robust than that of the U-shape: in every specification we report in the preceding paragraphs, it remains significant.

We also estimate the relationship using the Yatchew estimator described above. We do so using the simple measure $\frac{W E A L T H}{W E A L T H}$, that is household wealth relative to the village mean of household wealth. This allows us to remain agnostic about the functional form of the wealth dispersion variable. The results using both dependent variables (and SAMEITHR as the measure of correlation) are pictured in Figure 2. They are strikingly close to the theoretical prediction in that chances of having a group loan are minimized at the point of symmetry, that is when relative wealth equals one. (For reference, vertical hash lines are drawn through the curves where relative wealth equals one.) The probability of having a group loan increases the further from one is relative wealth. The effect is stronger on the margin for low relative wealth, but clearly seems present for high relative wealth as well, at least in the point estimates.

One might worry that the U-shape and the wealth dispersion are actually the same result: high- and low-wealth borrowers are more likely to take group loans. But recall that the U-shape relationship is the same for the whole sample, while the dispersion relationship is relative to village average wealth, and thus different in each village. Thus two poor households of equal wealth have the same boost to their chance of borrowing in a group due to the U-shape wealth level result, but a poor household from the richer village has an even higher boost due to the wealth dispersion result (since it is likely to be in a more asymmetric group). Of course, this interpretation relies on significant variation in village average wealth. This we have: the coefficient of variation of village average wealth is around two. ${ }^{47}$

\footnotetext{
${ }^{47}$ One might attribute the wealth dispersion result to rich people joining with their servants or poor neighbors merely to increase their loan size (by ex post appropriating the loan their servants receive). This seems unlikely. Most group-guaranteed loans are below 50,000 baht, while the mean individual loan is 87,000 and about $10 \%$ are over 200,000 . Thus applying individually seems to be a better way of obtaining a large loan. Further, a group loan is only given to an individual who can show that he is undertaking some agricultural project and has access to cultivated land (whether rented or owned), so above-mentioned scheme would be difficult to implement.
} 

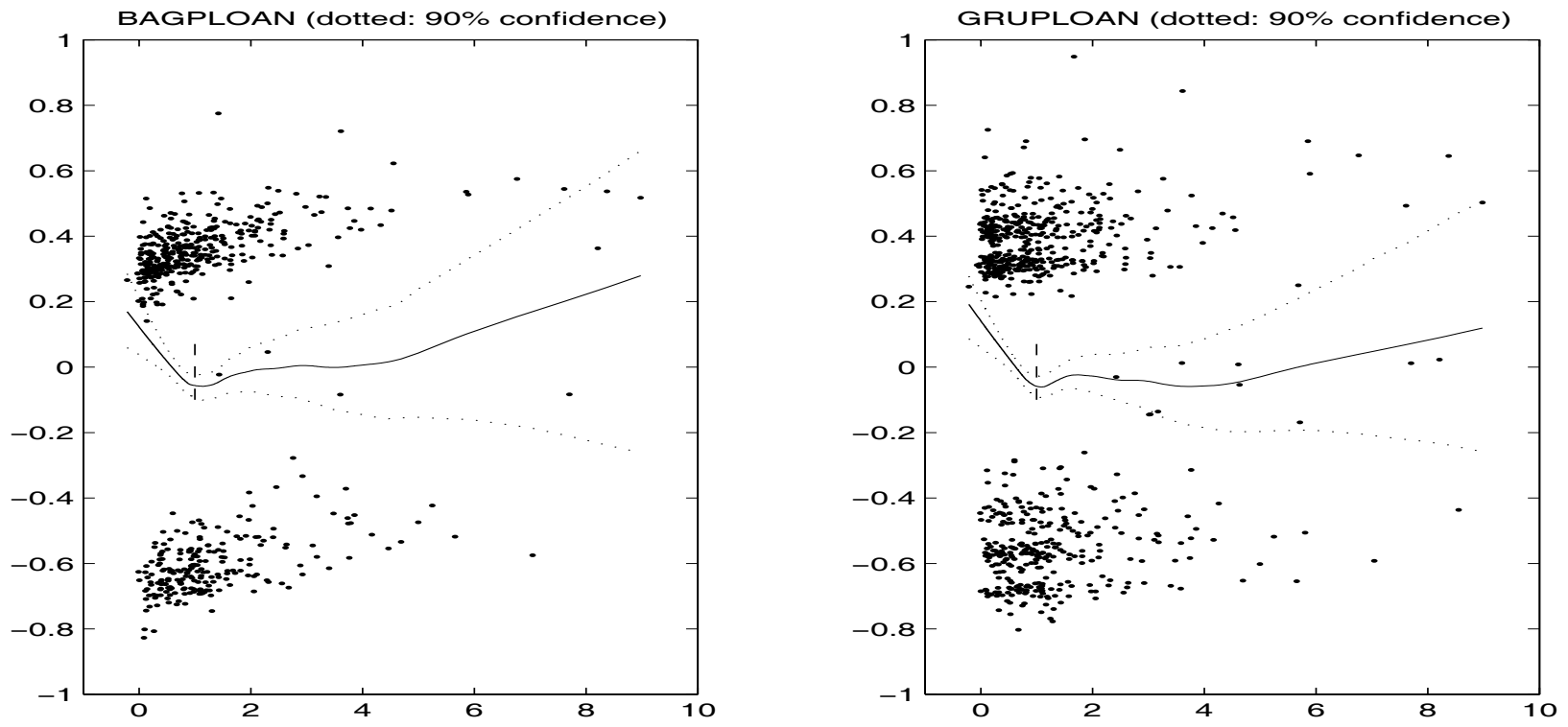

Figure 2: Relative wealth - household wealth divided by village mean - as a predictor of having a group loan.

With respect to technological correlation, none of the measures shows up significantly, except SAMEBEST at the 90\% level in the specification with GRUPLOAN as dependent variable. However, it shows up positively, counter to what HM predicts. Thus there is some evidence against, or at least no evidence for, the prediction of the HM model regarding correlation. It is plausible that the lack of result is due to a very noisy measure of correlation, but less so since we do get some results with the same variable when testing the Ghatak theory. $^{48}$

To test the HM model more faithfully, one would want to exclude EXINCOME. In their model, expected income equals a linear function of effort and the contract parameters, which are all endogenously determined. One might also want to include the variance of technology, as this is an exogenous parameter held constant in the comparison HM perform. We experimented with the exclusion of EXINCOME, with and without the inclusion of a measure of the variance, ${ }^{49}$ and the results did not change. Further, the variance was

\footnotetext{
${ }^{48}$ One might also wonder if this variable is endogenous, since the group contract may explicitly encourage internal risk-sharing and thus may induce high correlation within the group, at least for consumption and income net of risk-sharing. However, our measure makes this unlikely. It asks for the best or worst year in terms of a Thai word best translated as "income" or "earnings", and we believe this would generally be interpreted as income gross of risk-sharing transfers.

Further, we run correlations between two household indices for sharing rice, helping with free labor, and helping with money - plausible proxies for informal risk-sharing activity - with our three measures of household correlatedness. We thus compute six correlations, only two of which are significantly different from zero. Point estimates of the correlation are typically around .02 and always below .08. It appears safe to interpret our correlation measure as applying to income gross of informal risk-sharing transfers.

${ }^{49}$ The variance was measured using the subjective income assessments described above in section 3.2 . In particular, again assuming the binomial distribution on income over $\mathrm{Hi}$ and Lo, and calculating the probability of success using Ex, one can also calculate the variance as $(H i-E x)(E x-L o)$.
} 
not a significant predictor (nor have we explored what the model would predict about its implications). Thus the results reported in Table II are the same as those obtained from more faithful specifications.

None of the models incorporates the size of loan, desired or actual, though in theory this may be an important factor in determining the type of contract. ${ }^{50}$ It is important in the data also, as the BAAC has a de jure loan limit of fifty thousand baht for group loans but can give much higher individual loans. We therefore add loan size into the above specifications: once without sample restrictions, a second time excluding all households with loans greater than one hundred thousand, and a third time excluding all households with loans greater than fifty thousand. The latter samples allow comparisons over ranges of loans that are observed under either contract. The basic results are that loan size is a negative and significant predictor of the group regime, at the 1\% level always except under BAGPLOAN in the third sample, when it is at the $10 \%$ level. WLTHDSPR continues to be positive and significant at the $5 \%$ or $10 \%$ level. The U-shape on wealth continues to be seen in the coefficients on WEALTH and WEALTHSQ, but only in a minority of cases at conventional significance levels (most often the significance is 20-30\%). Correlation remains an insignificant predictor. In short, the slightly weakened significance of the U-shape relationship with wealth is the only change in results when controlling for loan.

The predictions of Ghatak are best tested in the full sample regressions, seen in Table III. This is because the selection there is between a group contract and some unspecified outside option (see discussion in section 3.1 and below for robustness checks). Correlation shows up as significant when GRUPLOAN is the dependent variable. Then it shows up positively and significantly at the 15\% level using SAMEBEST and SAMEWRST, and at the 5\% level using SAMEITHR. This is some evidence that households highly correlated with the rest of the village are more likely to borrow with a group contract. It provides support for the (modified) Ghatak model, which suggests that higher correlation reduces effective liability and thus makes joint liability borrowing more attractive.

The coefficient on PROBHI is always negative and significant. This is striking evidence for adverse selection in the joint liability credit market, as the Ghatak model predicts. The more likely a borrower is to succeed, the less likely he is to borrow in a joint liability group. The result is all the more remarkable because of the unique, literal interpretation we use to measure risk-type. ${ }^{51}$

Note that we have not identified adverse selection vis a vis moral hazard. A moral hazard interpretation of the data could be that risk was endogenous to having a group loan; that is, having the loan was causing the borrower to operate with more risk, rather than vice versa. In order to identify a pure adverse selection effect, we make use of the fact that some of the loans in our data have already been repaid (usually within the last few months). Under adverse selection, those who took a loan but have already repaid it would still be forecasting low probabilities of success, since they are inherently more risky. Under moral

\footnotetext{
${ }^{50}$ For a modification of Ghatak's model that incorporates endogenous loan size, see Ahlin and Townsend (2002).

${ }^{51}$ If the environment is such that every household is either endowed with a risky project or not endowed with any project, then our result could be spurious: both taking a loan and bearing risk could be the result of being endowed with a project. Our results do not seem to be driven by such a phenomenon, since we control for ownership of a business, agricultural occupation, and the desire to expand one's agricultural operation.
} 


\section{Table III -Full Samples}

The full sample is used in each of these regressions.

Standard errors in parentheses; significance at 5, 10, and $15 \%$ denoted by $* * *, * *$, and ${ }^{*}$, respectively.

\begin{tabular}{|c|c|c|c|c|c|c|}
\hline & \multicolumn{3}{|c|}{ BAGPLOAN } & \multicolumn{3}{|c|}{ GRUPLOAN } \\
\hline \multirow{2}{*}{ WEALTH } & -.077 & -.077 & -.077 & .016 & .016 & .015 \\
\hline & $(.078)$ & $(.078)$ & $(.078)$ & $(.067)$ & $(.068)$ & $(.068)$ \\
\hline \multirow{2}{*}{ WEALTHSQ } & $1.08 \mathrm{E}-9$ & $1.04 \mathrm{E}-9$ & $1.08 \mathrm{E}-9$ & $-1.37 \mathrm{E}-9$ & $-1.48 \mathrm{E}-9$ & $-1.43 \mathrm{E}-9$ \\
\hline & $(2.81 \mathrm{E}-9)$ & $(2.84 \mathrm{E}-9)$ & $(2.81 \mathrm{E}-9)$ & $(2.85 \mathrm{E}-9)$ & $(2.96 \mathrm{E}-9)$ & $(2.91 \mathrm{E}-9)$ \\
\hline \multirow{2}{*}{ WLTHDSPR } & .119 & .130 & .123 & -.098 & -.078 & -.084 \\
\hline & $(.176)$ & $(.176)$ & $(.176)$ & $(.164)$ & $(.165)$ & $(.165)$ \\
\hline \multirow{2}{*}{ TITLE } & .017 & .014 & .014 & -.125 & -.124 & -.127 \\
\hline & $(.110)$ & $(.110)$ & $(.110)$ & $(.071)^{* *}$ & $(.071)^{* *}$ & $(.071)^{* *}$ \\
\hline \multirow{2}{*}{ TITLESQ } & $-3.30 \mathrm{E}-9$ & $-3.09 \mathrm{E}-9$ & $-3.16 \mathrm{E}-9$ & $2.21 \mathrm{E}-9$ & $2.30 \mathrm{E}-9$ & $2.29 \mathrm{E}-9$ \\
\hline & $(6.06 \mathrm{E}-9)$ & $(6.06 \mathrm{E}-9)$ & $(6.04 \mathrm{E}-9)$ & $(2.80 \mathrm{E}-9)$ & $(2.90 \mathrm{E}-9)$ & $(2.84 \mathrm{E}-9)$ \\
\hline \multirow{2}{*}{ PROBHI } & -.460 & -.431 & -.448 & -.386 & -.344 & -.353 \\
\hline & $(.235)^{* * *}$ & $(.236)^{* *}$ & $(.235)^{* *}$ & $(.218)^{* *}$ & $(.219) *$ & $(.218)^{*}$ \\
\hline \multirow[t]{2}{*}{ SAMEBEST } & $\begin{array}{l}-.008 \\
(260)\end{array}$ & & & .370 & & \\
\hline & $(.269)$ & & & $(.251)^{*}$ & & \\
\hline \multirow[t]{2}{*}{ SAMEWRST } & & $\begin{array}{c}.351 \\
(989)\end{array}$ & & & $\begin{array}{c}.408 \\
(279) *\end{array}$ & \\
\hline & & $(.289)$ & & & $(.272)^{*}$ & \\
\hline \multirow{2}{*}{ SAMEITHR } & & & .331 & & & .784 \\
\hline & & & $(.367)$ & & & $(.346)^{* * *}$ \\
\hline \multirow{2}{*}{ INCOME } & .611 & .605 & .603 & .049 & .042 & .035 \\
\hline & $(.559)$ & $(.562)$ & $(.560)$ & $(.508)$ & $(.513)$ & $(.511)$ \\
\hline \multirow{2}{*}{ EXINCOME } & -.578 & -.565 & -.563 & .066 & .075 & .087 \\
\hline & $(.672)$ & $(.674)$ & $(.672)$ & $(.591)$ & $(.596)$ & $(.594)$ \\
\hline \multirow{2}{*}{ NRTHEAST } & .618 & .603 & .600 & .317 & .326 & .301 \\
\hline & $(.133)^{* * *}$ & $(.133)^{* * *}$ & $(.134)^{* * *}$ & $(.122)^{* * *}$ & $(.121)^{* * *}$ & $(.122)^{* * *}$ \\
\hline \multirow{2}{*}{ AGRYES } & 1.03 & 1.03 & 1.02 & 1.16 & 1.17 & 1.15 \\
\hline & $(.244)^{* * *}$ & $(.244)^{* * *}$ & $(.244)^{* * *}$ & $(.214)^{* * *}$ & $(.213)^{* * *}$ & $(.214)^{* * *}$ \\
\hline \multirow{2}{*}{ AGRNO } & .761 & .753 & .752 & .737 & .735 & .725 \\
\hline & $(.251)^{* * *}$ & $(.251)^{* * *}$ & $(.252)^{* * *}$ & $(.221)^{* * *}$ & $(.221)^{* * *}$ & $(.221)^{* * *}$ \\
\hline \multirow{2}{*}{ OWNBSNS } & .280 & .294 & .287 & .079 & .093 & .093 \\
\hline & $(.152)^{* *}$ & $(.153)^{* *}$ & $(.153)^{* *}$ & $(.141)$ & $(.142)$ & $(.142)$ \\
\hline \multirow{2}{*}{ LANDOWND } & $4.21 \mathrm{E}-3$ & $4.13 \mathrm{E}-3$ & $4.19 \mathrm{E}-3$ & $4.17 \mathrm{E}-3$ & $4.01 \mathrm{E}-3$ & $4.09 \mathrm{E}-3$ \\
\hline & $(2.68 \mathrm{E}-3)^{*}$ & $(2.67 \mathrm{E}-3)^{*}$ & $(2.67 \mathrm{E}-3)^{*}$ & $(2.36 \mathrm{E}-3)^{* *}$ & $(2.36 \mathrm{E}-3)^{* *}$ & $(2.35 \mathrm{E}-3)^{* *}$ \\
\hline \multirow{2}{*}{ EDYEARH } & .037 & .038 & .038 & .056 & .057 & .057 \\
\hline & $(.024)^{*}$ & $(.024)^{*}$ & $(.024) *$ & $(.023) * * *$ & $(.023) * * *$ & $(.023)^{* * *}$ \\
\hline \multirow{2}{*}{ MALEH } & .510 & .508 & .504 & .468 & .476 & .467 \\
\hline & $(.168)^{* * *}$ & $(.168)^{* * *}$ & $(.168)^{* * *}$ & $(.152)^{* * *}$ & $(.152)^{* * *}$ & $(.152)^{* * *}$ \\
\hline$N$ & 1666 & 1666 & 1666 & 1602 & 1602 & 1602 \\
\hline
\end{tabular}


hazard, the incentives for risk-taking from having a limited liability loan vanish when the loan is repaid, so those who have already repaid their loan should look no different from those who never had a loan. We run the logits again after eliminating all households with a group loan that has not yet been repaid. Unfortunately, this leaves less than $20 \%$ of the households who had group loans. In all specifications, the coefficient actually increases noticeably in magnitude (i.e. becomes more negative), but so do the standard errors. In the three specifications using BAGPLOAN, PROBHI remains significant, twice at the $10 \%$ level and once at the $15 \%$ level. In the specifications using GRUPLOAN, the estimates drop just beyond conventional significance levels (15-30\%). This may be expected from the significant drop in sample size. We interpret these results as suggestive that adverse selection specifically is occurring in this credit market. ${ }^{52}$

The previous test provides evidence for adverse selection, but it does not rule out that moral hazard is also occurring. One can approach the moral hazard question in a similar way. ${ }^{53}$ Among those who took a loan, moral hazard suggests that those who have already repaid should look less risky than those with a loan still outstanding. Again, the reason is that the incentives for risk-taking disappear once the loan is repaid. We therefore limit the sample to those who did take out a loan (those for whom BAGPLOAN or GRUPLOAN, depending on the specification, equals one) and predict PROBHI using the same covariates as above and a dummy for whether the loan is already repaid. Contrary to what theory would predict, the coefficient on the dummy is negative and insignificant in all six specifications, using both OLS and tobit. The data here thus provide no evidence that moral hazard is occurring. ${ }^{54}$

One might argue that when testing adverse selection, individual loans should not be included in the outside option $(D=0$, where $D=1$ represents having a loan) but as part of those having a loan $(D=1)$. It is only limited liability that is needed for adverse selection, irrespective of whether liability is individual or joint. If the individual loans, though technically collateralized, are in fact limited liability to some degree, they should also exhibit adverse selection. Accordingly, we rerun the specifications in Table III coding households that have individual loans as $D=1$. We also skirt the issue by running them again excluding all households that have an individual loan. The results in both cases change little, ${ }^{55}$ or if anything become sharper. These results may suggest that the individual loans exhibit limited liability, and thus are subject to adverse selection, but both to a lesser degree

\footnotetext{
${ }^{52}$ It is unlikely that our lender observes the information contained in PROBHI or something similar. Regardless, the lender was not using information to tailor the contract (except for loan size), but was offering a standard contract to whoever wanted it.

${ }^{53}$ We thank Eric Bond for suggesting the following test.

${ }^{54}$ Note that moral hazard here in the Stiglitz/Weiss and Ghatak sense refers to effects on the riskiness, not mean, of the distribution.

${ }^{55}$ Specifically, the coefficient on PROBHI is negative and significant at $10 \%$ in every specification when individual loans are excluded. It is negative and significant at $5 \%$ in the first and third specifications and $10 \%$ in the remaining four when individual loans are included with group loans.

Oddly enough, SAMEWRST becomes an even stronger predictor of borrowing when individual loans are included with group loans. The result we show in section 2.3 cannot explain this since it relies on joint liability specifically, not just limited liability. One interpretation we do not explore here is that if all loans are insurance contracts bought at some price, those with the least ability to ensure themselves (i.e. high correlation of bad years) would be the ones buying them. (The frameworks of HM and PT hint at this, though they restrict analysis to the choice of contract given a contract is bought.)
} 
than group loans. ${ }^{56}$ Thus, whether they are included with group loans or the outside option, we expect the adverse selection result.

\section{Conclusion}

The results on wealth and contract selection are interesting in several respects. Indirectly, they give plausibility to the interpretation of group lending as a way for the lender to promote side-contracting between borrowers. This has not always been the primary view of group lending, but it does appear to have some empirical validity.

More directly, these results confirm the PT emphasis on wealth distribution as a key determinant of the optimal contract. Specifically here, a wealth level further away from the village average, or further away from the population cutoff of 6-8 million baht, makes choice of a group loan over an individual loan more likely. From a theoretical point of view, moving away from a transferable utility framework seems warranted. From a policy point of view, one might be led to wonder whether group lending accomplishes its goal of reducing inequality, or whether, at least locally, it thrives on inequality and perhaps perpetuates it through unequal intra-group allocation of consumption and labor.

The absence of corroboration in the data for the HM result is puzzling. One reason could be that correlation is unobservable by the lender. It is less likely to be due to the noisiness of our correlation measure, since the measure does appear positively and significantly in the Ghatak specification, as predicted.

The results confirming Ghatak on adverse selection and correlation indirectly support the more common interpretation of group lending as joint liability. Though we do not view this interpretation as necessarily contradictory with the other, we know of no attempt to analyze their interaction. This attempt could lead to fruitful research.

At any rate, adverse selection of risky borrowers seems to be an issue not only in the ivory tower, but also in the rice patties. In terms of policy, at least partial screening by risk information that is available is an obvious first step in improving the extension of credit and the allocation of funds. Since the survey, the BAAC has in fact begun offering different interest rates depending on credit history. Still, there may remain room for more efficient screening by offering a wider array of contracts with different combinations of interest rate and joint liability (as in Ghatak 2000). On the theoretical front, introducing loan size into such an adverse selection model could also prove fruitful.

\footnotetext{
${ }^{56}$ If this were true, we would expect the magnitude of the coefficients on PROBHI to be highest when individual loans are excluded altogether, since the comparison would be starkest in that case. Indeed, this is what we find.
} 


\section{References}

[1] Christian Ahlin and Robert M. Townsend. Using repayment data to test across theories of joint liability lending. Working Paper, December 2002.

[2] Lawrence M. Ausubel. Adverse selection in the credit card market. Working Paper, University of Maryland, June 17, 1999.

[3] Pierre-Andre Chiappori, Bruno Jullien, Bernard Salanie, and Francois Salanie. Asymmetric information in insurance: Some testable implications. Working Paper, September 16, 2002.

[4] Pierre-Andre Chiappori and Bernard Salanie. Testing contract theory: A survey of some recent work. Forthcoming, Advances in Economic Theory.

[5] W. S. Cleveland. Robust locally weighted regression and smoothing scatterplots. Journal of the American Statistical Association, 74:829-836, 1979.

[6] Jianqing Fan. Design-adaptive nonparametric regression. Journal of the American Statistical Association, 87(420):998-1004, December 1992.

[7] Maitreesh Ghatak. Group lending, local information and peer selection. Journal of Development Economics, 60(1):27-50, October 1999.

[8] Maitreesh Ghatak. Screening by the company you keep: Joint liability lending and the peer selection effect. Economic Journal, 110(465):601-631, July 2000.

[9] Bengt Holmstrom and Paul Milgrom. Regulating trade among agents. Journal of Institutional and Theoretical Economics, 146(1):85-105, March 1990.

[10] Edward Simpson Prescott and Robert M. Townsend. Collective organizations versus relative performance contracts: Inequality, risk sharing, and moral hazard. Journal of Economic Theory, 103(2):282-310, April 2002.

[11] Marguerite S. Robinson. The Microfinance Revolution: Sustainable Finance for the Poor. World Bank, Washington, D.C., 2001.

[12] Joseph E. Stiglitz and Andrew Weiss. Credit rationing in markets with imperfect information. American Economic Review, 71(3):393-410, June 1981.

[13] Robert M. Townsend and Jacob Yaron. The credit risk-contingency system of an asian development bank. Federal Reserve Bank of Chicago Economic Perspectives, XXV:3148, 2001.

[14] Adonis Yatchew. Nonparametric regression techniques in economics. Journal of Economic Literature, 36:669-721, June 1998. 